\title{
The hepatic pre-metastatic niche in pancreatic ductal adenocarcinoma
}

\author{
Demi S. Houg ${ }^{1}$ and Maarten F. Bijlsma ${ }^{1,2^{*}}$ (D)
}

\begin{abstract}
Pancreatic ductal adenocarcinoma (PDAC) remains one of the most aggressive malignancies to date, largely because it is associated with high metastatic risk. Pancreatic tumors have a characteristic tendency to metastasize preferentially to the liver. Over the past two decades, it has become evident that the otherwise hostile milieu of the liver is selectively preconditioned at an early stage to render it more conducive to the engraftment and growth of disseminated cancer cells, a concept defined as pre-metastatic niche (PMN) formation. Pancreatic cancer cells exploit components of the tumor microenvironment to facilitate their migration out of the primary tumor, which often involves conversion of pancreatic cancer cells from an epithelial to a mesenchymal phenotype via the epithelial-to-mesenchymal transition. Pancreatic stellate cells and matrix stiffness have been put forward as major drivers of invasiveness in PDAC. Even before the onset of pancreatic cancer cell dissemination, soluble factors and extracellular vesicles secreted by the primary tumor, and possibly even premalignant lesions, help shape a supportive niche in the liver by providing vascular docking sites for circulating tumor cells, enhancing vascular permeability, remodeling the extracellular matrix and recruiting immunosuppressive inflammatory cells. Emerging evidence suggests that some of these tumor-derived factors may represent powerful diagnostic or prognostic biomarkers. Though our understanding of the mechanisms driving PMN formation in PDAC has expanded considerably, many outstanding questions and challenges remain. Further studies dissecting the molecular and cellular events involved in hepatic PMN formation in PDAC will likely improve diagnosis and open new avenues from a therapeutic standpoint.
\end{abstract}

Keywords: Pancreatic cancer, Metastasis, Niche, Stroma

\section{Background}

Metastatic spread of malignant cells continues to pose a problem to the treatment of cancer and remains the principal cause of cancer mortality, particularly in the case of pancreatic ductal adenocarcinoma (PDAC). The majority of patients with PDAC presents with systemic disease at the time of diagnosis and only $8 \%$ of patients survive for 5 years or longer following diagnosis [1]. Although surgical resection of the primary tumor remains the most effective strategy to extend patient survival, $85-90 \%$ of patients are considered ineligible owing to the systemic nature of the disease and a failure to detect the disease early [1-3]. Moreover, with more than $80 \%$ of patients suffering systemic spread following surgery, disease relapse is often the rule rather than the

\footnotetext{
* Correspondence: m.f.bijlsma@amc.uva.nl

${ }^{1}$ Laboratory for Experimental Oncology and Radiobiology, Center of Experimental and Molecular Medicine, Cancer Center Amsterdam and Academic Medical Center, Amsterdam, the Netherlands

${ }^{2}$ Oncode Institute, Academic Medical Center, Amsterdam, the Netherlands
}

exception [4]. Our increased understanding of pancreatic cancer biology [5-10] and advances in therapeutic approaches [11-13] have yet to translate into significant improvements in overall survival. Until then, the development of new treatments directed at metastatic spread of pancreatic cancer cells may prove particularly valuable, underscoring the need for further research into the pathogenesis of pancreatic cancer metastasis.

A growing body of research has demonstrated that cancer cells metastasize to the milieu of specific organs with a predetermined selectivity. The concept of organ selectivity of metastasis, or organotropism, was first introduced by Stephen Paget in 1889 in the form of the seed and soil hypothesis [14]. Based on the non-random distribution of metastases in patients with breast cancer, he hypothesized that cancer cells (the "seeds") home exclusively to organs that are conducive to their survival and growth (the fertile "soil"). Autopsy studies investigating the localization of metastases in patients with 
PDAC have revealed that pancreatic carcinoma cells metastasize disproportionately to the liver. Liver metastases are found in $76-80 \%$ of patients; other common sites of metastasis include the peritoneum (48\%) and the lungs $(45 \%)[15,16]$.

Many efforts in the field of metastasis have centered on molecular and genetic alterations that determine the metastatic capacity of certain tumor cells. However, as the efficiency of metastasis is limited by continuous immune surveillance, apoptosis and other barriers [17], tumor cell-intrinsic properties alone are insufficient for successful metastatic seeding and outgrowth [18]. Our understanding of metastasis has advanced significantly in recent years and various fundamental discoveries have added an additional layer of complexity to the original seed and soil hypothesis. There is a growing appreciation that primary tumors precondition the microenvironments of future sites of metastasis to form so-called pre-metastatic niches (PMNs) that support the engraftment, survival and outgrowth of circulating tumor cells even prior to their arrival [18-21]. The development of PMNs is governed by a complex series of reciprocal interactions between tumor cells and various components of the tumor microenvironment, as well as the exploitation of resident and recruited cells in secondary target organs. The current review aims to describe the emerging knowledge base with regard to mechanisms involved in the formation of the hepatic PMN and subsequent metastasis in PDAC, and highlights some of the opportunities and challenges regarding the translation of these mechanistic insights into promising diagnostic and therapeutic approaches. To this end, we will first discuss several cues from the tumor microenvironment that prompt pancreatic cancer cells to migrate out of the primary tumor, before moving on to the extrinsic and intrinsic factors that help shape a permissive niche in the liver for colonization by disseminated tumor cells.

\section{The role of the epithelial-to-mesenchymal transition in the metastatic cascade}

Metastasis is a multistep process involving localized migration, intravasation into and transport through the lymphatic system or the systemic circulation, followed by extravasation at distant capillaries, the development of micrometastases, and ultimately macrometastatic colonization [22]. Hence, a crucial step in the metastatic cascade is the acquisition of migratory and invasive properties. This requires pancreatic cancer cells to exchange many of their epithelial characteristics, such as apical-basal polarity and cell-cell adhesion, for mesenchymal traits via a cellular program known as epithelial-to-mesenchymal transition (EMT) [23]. Though first identified in the context of embryonic morphogenesis [24], in recent years EMT has also become prominently implicated in wound resolution, fibrosis, tissue regeneration and cancer progression [25]. Molecular changes associated with this transition include the loss of epithelial markers like E-cadherin, cytokeratins, occludin and claudin, and the gain of mesenchymal markers such as $\mathrm{N}$-cadherin, vimentin and fibronectin [25, 26]. In addition, cells that have switched to the mesenchymal state adopt a spindle-like shape rather than the columnar shape that is typical of epithelial cells. The mesenchymal phenotype following induction of EMT is characterized by enhanced migratory capacity, invasiveness, increased resistance to apoptosis and elevated production of extracellular matrix (ECM) components [25].

The functional role of EMT in invasion and metastasis has recently been challenged by Zheng and colleagues, who reported that rates of metastases in genetically engineered mouse models of PDAC were not affected by knockout of Snai1 or Twist1, two genes encoding EMT-inducing transcription factors [27]. Consequently, the authors drew the contentious conclusion that EMT is dispensable for metastatic dissemination of pancreatic cancer cells. Recently, however, Aiello and co-workers highlighted several caveats that cast doubt on the validity of their claims, including the fact that the study involved the use of a marker of EMT deemed unreliable in the selected mouse model [28]. Secondly, EMT is a highly complex cellular program that is regulated through multiple molecular pathways, some of which remain incompletely understood. Genetic deletion of either Snai1 or Twist1 may have failed to effectively abolish all manifestations of EMT. This is corroborated by the finding that conditional knockout of another EMT activator, Zeb1, in the same mouse model in fact strongly influences malignant progression of PDAC [29]. Knockout of Zeb1 had detrimental effects on cell plasticity and fixed pancreatic tumor cells in an epithelial state. This was accompanied by a remarkable reduction in local invasion in the primary tumor as well as in the capacity of tumor cells to colonize and metastasize to distant organs, which is in sharp contrast to the findings of Zheng et al. following Snai1 or Twist1 depletion. Krebs and colleagues concluded that different EMT transcription factors may have distinct and tissue-specific functions that are complementary rather than redundant. In this regard, Snai1 and Twist1 may indeed be dispensable for metastatic progression of PDAC, but the critical role of the EMT activator Zeb1 in this cancer type means that we cannot dismiss EMT as a fundamental event preceding invasion and metastasis of pancreatic cancer [25].

Nonetheless, the study by Zheng et al. did uncover an unexpected relationship between Snai1- and Twist1-dependent EMT and chemotherapy resistance. It was already demonstrated in a previous study that Zeb1-mediated EMT contributes to resistance to gemcitabine, 5-fluorouracil and cisplatin in various pancreatic cancer cell lines [30]. 
Knockdown of Zeb1 increased the expression of epithelial markers and restored drug sensitivity. Zheng et al. elaborated on these findings by showing that knockout of Snai1 or Twist1 in a KPC mouse model of PDAC correlated with an increase in drug sensitivity and overall survival of gemcitabine-treated mice [27]. Enhanced drug sensitivity coincided with upregulated expression of drug transporters, providing a potential mechanistic underpinning for the link between EMT and chemoresistance in PDAC. These data further accentuate the eminent role of EMT in the progression of PDAC.

\section{Support from the stroma in tumor cell migration and invasion}

The acquisition of migratory and invasive properties is not only driven by genetic perturbations that have evolved during tumor development. Rather, the interplay between tumor cells and their microenvironment represents another critically important driver of tumor cell invasion and metastasis. Histologically, a prominent characteristic of PDAC is the extensive fibrotic response surrounding neoplastic cells (also known as desmoplasia or tumor-associated stroma), which may constitute up to $80 \%$ of the total tumor volume [31, 32]. In the stroma of normal epithelial tissues, tissue homeostasis is maintained by a dynamic network of fibroblasts, inflammatory cells, ECM and vasculature composed of endothelial cells and pericytes [33]. By contrast, in the stroma surrounding pancreatic cancer tissue, these cellular and acellular components are conscripted and corrupted by pancreatic cancer cells to form a tumor-promoting environment which stimulates cancer cell proliferation [34, 35] and migration [36, 37], and serves as a reservoir for cytokines and growth factors [38]. Furthermore, the tumor-associated stroma in PDAC forms a barrier to the delivery of multiple therapeutic agents $[39,40]$ and conveys chemo- and radioresistance [34, 41]. In the following section, we will discuss how the stroma in PDAC spurs pancreatic cancer cells to migrate out of the primary tumor to set the stage for systemic spread.

\section{Dynamic interplay between activated pancreatic stellate} cells and pancreatic cancer cells drives malignant behaviour The principal cells responsible for PDAC-associated fibrogenesis are activated fibroblasts or myofibroblasts, the most abundant cell type in the desmoplastic stroma of PDAC [42]. While these myofibroblasts may also originate from pancreas-resident fibroblasts or from bone marrow-derived mesenchymal stem cells, a prominent source of myofibroblasts in PDAC are pancreatic stellate cells (PSCs). Repeated or sustained pancreatic injury causes the transformation of normally quiescent PSCs into aberrantly activated, fibroblastic cells, leading to enhanced deposition of ECM proteins such as collagen and fibronectin [33]. Clinically, there is an inverse correlation between the extent of PSC activation and prognosis in PDAC patients, highlighting the role of PSCs in pancreatic cancer progression [32].

Both in vitro and in vivo studies have revealed the existence of an intricate bidirectional crosstalk between pancreatic cancer cells and PSCs which fosters both local tumor growth and distant metastasis. Pancreatic cancer cells promote the chemotactic recruitment of PSCs to their vicinity via the secretion of platelet-derived growth factor (PDGF) [43, 44]. Simultaneously, PDGF has direct mitogenic effects on PSCs and thus stimulates their proliferation [45]. Pancreatic cancer cells also release fibrogenic mediators such as transforming growth factor $\beta 1$ (TGF $\beta 1$ ) which stimulate the synthesis and deposition of ECM components by activated PSCs. In turn, PSCs contribute to pancreatic cancer cell survival by promoting their proliferation, suppressing apoptosis and possibly protecting them from chemo- and radiotherapy $[34,44]$. In a recent study, cancer-associated fibroblasts (CAFs) and PSCs were found to constitute not merely a biophysical barrier to gemcitabine delivery but in fact take up the drug and trap its active metabolite intracellularly as a result of downregulated expression of gemcitabine-inactivating enzymes and transporters, thereby reducing the amount of drug available to cancer cells [46].

In the context of metastasis, PSCs have emerged as one of the key effector cells in the shift of pancreatic cancer cells toward the more motile, mesenchymal state. Pancreatic cancer cells co-cultured with human PSCs (hPSCs) assume a fibroblastic morphology, and exhibit transcriptional downregulation of the epithelial markers E-cadherin and cytokeratin 19 and upregulation of the mesenchymal markers vimentin and Snai1, concomitant with a marked increase in pancreatic cancer cell motility [47]. In an attempt to recapitulate the influence of the stromal compartment on tumor progression in vivo, Hwang et al. used an orthotopic mouse model of PDAC to investigate the incidence of metastasis. Co-injection of human pancreatic cancer cells and hPSCs into mice resulted in an increase in the number of distant metastases proportional to the relative number of stellate cells present in the mixture. Distant metastases could be found even when a limiting number of cancer cells was injected, further emphasizing that the dynamic interplay between pancreatic cancer cells and PSCs creates a favorable microenvironment that nourishes malignant behavior.

There have been multiple endeavors to delineate the molecular mechanisms underlying the influence of PSCs on the invasive capacity of pancreatic cancer cells. Given that conditioned medium from isolated hPSCs significantly enhances pancreatic cancer cell invasion, the observed pro-metastatic effects of PSCs appear to be 
mediated largely by soluble factors [34]. One factor that has been intensively studied with respect to pancreatic cancer cell invasion is stromal-derived factor-1 (SDF-1). Secretion of TGF $\beta$ by pancreatic cancer cells can stimulate SDF-1 production and secretion by PSCs via the upregulation of galectin-1 [48]. Pancreatic cancer cells express high levels of the SDF-1 receptor $\mathrm{C}-\mathrm{X}-\mathrm{C}$ chemokine receptor 4 (CXCR4) [49]. Interaction of SDF-1 with CXCR4 induces EMT in pancreatic cancer cells, allowing them to migrate along gradients of SDF-1 generated by PSCs. In another study, the presence of stromal fibroblasts increased pancreatic cancer cell expression of a set of genes linked to tumor cell invasion, including $c y$ clooxygenase 2 (COX-2)/prostaglandin-endoperoxide synthase 2 (PTGS2), hyaluronan synthase 2 (HAS2), and matrix metalloproteinase-1 (MMP-1) [50]. Constitutive expression of COX-2 has previously been shown to increase the metastatic potential of human colorectal cancer cells in vitro [51]. The increased invasiveness of these cells was associated with elevated activation of MMP-2, which mediates proteolytic degradation of the ECM and thus facilitates cancer cell migration [52]. A similar role for COX-2 overexpression in PDAC seems plausible, as it has been reported that downregulation of COX-2 expression represses tumor cell invasiveness and motility in various pancreatic cancer cell lines and reduces the number of liver metastases in an orthotopic mouse model of PDAC [53, 54].

Hyaluronan is a glycosaminoglycan that is markedly enriched in the ECM surrounding pancreatic tumors [55], and has previously been reported to stimulate motility and invasion in cell culture models of fibrosarcoma [56], colon cancer [57] and prostate cancer [58]. In PDAC, tumor-associated stromal fibroblasts induce the expression of HAS2 in pancreatic cancer cells, thereby enhancing the rate of synthesis and deposition of hyaluronan [50]. Subsequent accumulation of hyaluronan in the tumor microenvironment stimulates pancreatic cancer cell motility [37] and enhances the frequency of metastasis [59]. The stimulatory effect of hyaluronan on cell motility may be linked to its centrally important role in EMT. In mice, a lack of hyaluronan during embryonic development abrogates the ability of cardiac endothelial cells to undergo EMT and disrupts cardiac morphogenesis [60]. Furthermore, overproduction of hyaluronan induces EMT in non-transformed epithelial cells, with increased anchorage-independent growth and invasiveness as a result [61]. In pancreatic cancer cells, increased production of hyaluronan leads to loss of E-cadherin and cytoplasmic accumulation of $\beta$-catenin, suggesting that hyaluronan may promote pancreatic cancer cell motility by inducing EMT [62].

The formation of new blood vessels is an integral hallmark of cancer [63] and not only provides tumor sustenance in the form of oxygen and nutrients, but could also represent a way to increase the potential for metastatic spread [64]. PSCs are believed to interact closely with endothelial cells in order to promote angiogenesis. By secreting pro-angiogenic mediators such as vascular endothelial growth factor (VEGF), PSCs can induce tube formation in vitro [65, 66] and increase the population of endothelial cells in an orthotopic mouse model of PDAC [66]. It is worth noting, however, that the central areas of pancreatic tumors are notoriously hypovascularized and thus highly hypoxic, while a higher degree of vascularity is evident at the periphery of the tumor [39]. Nonetheless, hypoxia has long been recognized to elicit malignant behavior and actually serves as a cue for VEGF secretion and the induction of pro-angiogenic responses by PSCs $[65,67]$. Thus, perhaps tumor hypoxia triggers PSCs to instruct endothelial cells to generate new capillary beds specifically at the invasive front of the tumor [68], with the aim to facilitate proliferation and metastatic dissemination of pancreatic cancer cells.

Interestingly, cells positive for $\alpha$-smooth muscle actin ( $\alpha$ SMA) - a marker of activated PSCs - and even PSCs themselves have been detected in distant metastases [44, 66, 69], which calls into question the common perception that systemic spread is solely restricted to cancer cells. In fact, PSCs have been observed to migrate through an endothelial cell monolayer in response to pancreatic cancer cell-derived PDGF [66]. Another study using an organotypic model of PDAC showed that nuclear translocation of fibroblast growth factor 2 (FGF2) and fibroblast growth factor receptor 1 (FGFR1) in PSCs drives invasion of both PSCs and pancreatic cancer cells into the surrounding ECM [70]. In tissue sections of PDAC, myofibroblasts with nuclear FGF2 and FGFR1 are abundant at the invasive front but not in central areas of the tumors. These data support a model in which PSCs actually have the capacity to co-migrate with pancreatic cancer cells to future metastatic sites, where they could potentially assist their seeding, survival and proliferation.

\section{Matrix stiffness as a pro-migratory cue}

More recently, biomechanical properties of the stromal compartment have gained increasing interest as mediators of tumor cell behaviour in PDAC. The ECM comprises a diverse array of macromolecules including collagens, fibronectin and proteoglycans, the concentrations and post-translational modifications of which are normally tightly controlled [71]. Disruption of ECM homeostasis during tumor progression - as a result of persistent activation of PSCs - is characterized by increased deposition, altered organization and crosslinking of ECM components, giving rise to a particularly rigid matrix. Though the ECM has historically been regarded as merely a structural scaffold and barrier to tumor cell migration, it is now increasingly acknowledged that 
matrix stiffness associated with the desmoplastic reaction can provide biomechanical cues that modulate intracellular signaling pathways and augment tumor malignancy.

Sensing of mechanical forces by cells is mediated by integrins. In response to exogenous forces imposed on cells, integrins aggregate into focal adhesion complexes at the cell membrane to initiate downstream signaling events, thereby transducing mechanical inputs into biochemical outputs [72, 73]. In a variety of pancreatic cancer cell lines, extracellular stiffness is associated with elevated expression of vimentin, reduced expression of E-cadherin, and nuclear localization of $\beta$-catenin, YAP and TAZ, changes known to be linked to EMT [74]. The extent to which pancreatic cancer cells undergo EMT is dependent on the degree of matrix rigidity. Gradual increases in matrix rigidity parallel with tumor progression promote mesenchymal behavior in a progressive manner, illustrating that EMT is not just a binary switch between two cellular phenotypes, but rather a highly plastic transition. The molecular pathway underlying stiffness-induced EMT has recently been explored in mammary epithelial cells and involves a potential role for Twist1 as a mechanotransducer [75]. In the absence of mechanical stimuli, this EMT-associated transcription factor is retained in the cytoplasm by G3BP2. In response to matrix stiffness and subsequent integrin activation, the interaction between Twist1 and G3BP2 is disrupted through phosphorylation of a tyrosine residue within the G3BP2-binding motif of Twist1, allowing Twist1 to enter the nucleus and induce an EMT transcriptional program. Whether a similar mechanotransduction pathway drives stiffness-induced EMT in PDAC remains a matter of speculation.

Besides adopting pro-migratory mesenchymal properties, pancreatic cancer cells respond to stiff microenvironments by enhancing cellular contractility through the Rho/ROCK pathway downstream of integrin activation $[72,75]$. This shift to a contractile state is associated with augmented activity of matrix metalloproteinases (MMPs), a family of endopeptidases which functions predominantly to degrade matrix proteins [75]. A dense and highly crosslinked ECM represents a physical barrier that needs to be compromised in order for tumor cells to migrate out of the primary tumor and intravasate into blood vessels. Thus, it has been postulated that pancreatic cancer cells tactfully tune MMP activity according to the stiffness of their surroundings to facilitate their emigration [75].

On the other hand, dynamic regulation of MMP activity is also required to prevent excessive degradation of the ECM, as type I collagen secreted from PSCs plays a key role in pancreatic cancer cell motility. Though collagen I is a well-established mediator of EMT in pancreatic cancer cells [76-78], it also orchestrates pro-migratory mechanisms that are much less time-consuming. Carcinoma cells exploit thickened, linearized collagen bundles of the ECM as tracks for directional migration within the tumor [71]. Indeed, migration of carcinoma cells in highly metastatic breast tumors appears to be guided by collagen fibres [79]. Likewise, pancreatic cancer cells interact with PSC-secreted collagen I via the $\alpha 2 / \beta 1$ integrin-focal adhesion kinase (FAK) signaling pathway and use it directly as a low-resistance scaffold to adhere to and migrate along [80]. Furthermore, alignment of collagen fibres has been observed in PDAC in vivo [81], and intravital microscopy of pancreatic tumors has shown migratory cells orienting their protrusions toward collagen fibres [82], suggesting an important role for stiffened collagen fibres in pancreatic cancer metastasis.

\section{Preparing the soil: Primary tumor-derived factors drive hepatic PMN formation}

Once pancreatic cancer cells have acquired the capacity to invade, systemic spread is underway. Egress from the primary tumor, however, is only the first hurdle to clear on the way to successful metastasis. Mouse models of PDAC have demonstrated that up to $68 \%$ of pancreatic cancer cells are capable of fully completing an EMT program, and, more strikingly, that circulating tumor cells can be detected even before a detectable tumor arises at the primary site [83]. Despite this, no more than $0.01 \%$ of cells ultimately end up establishing metastatic outgrowths [84], which goes to show just how inefficient the process of metastasis really is. Therefore, it is of paramount importance that the primary tumor preconditions the otherwise hostile microenvironment of the secondary site such that it can sustain metastatic colonization. The stepwise evolution of the hepatic PMN is initiated early during the progression of PDAC, possibly already during premalignant phases. Given that research into hepatic PMN development in PDAC is still in its infancy, the following section will not encompass an exhaustive list of pro-metastatic mediators. Rather, this section aims to provide a detailed understanding of how tumor-secreted factors in PDAC contribute to the metastatic success of disseminated pancreatic cancer cells by transforming the liver into a hospitable niche (Fig. 1), with a focus on tissue factor (TF), tissue inhibitor of metalloproteinases-1 (TIMP-1) and exosomes.

\section{Tissue factor-induced thrombus formation shows circulating pancreatic cancer cells the way out}

Pancreatic cancer patients have long been recognized to be at a higher risk of venous thromboembolism [85]. Platelets are key players in thrombosis, and many studies have linked platelet count and activity to metastatic potential and poor outcome in PDAC [86-91]. Tumor cells have been shown to interact closely with platelets and 


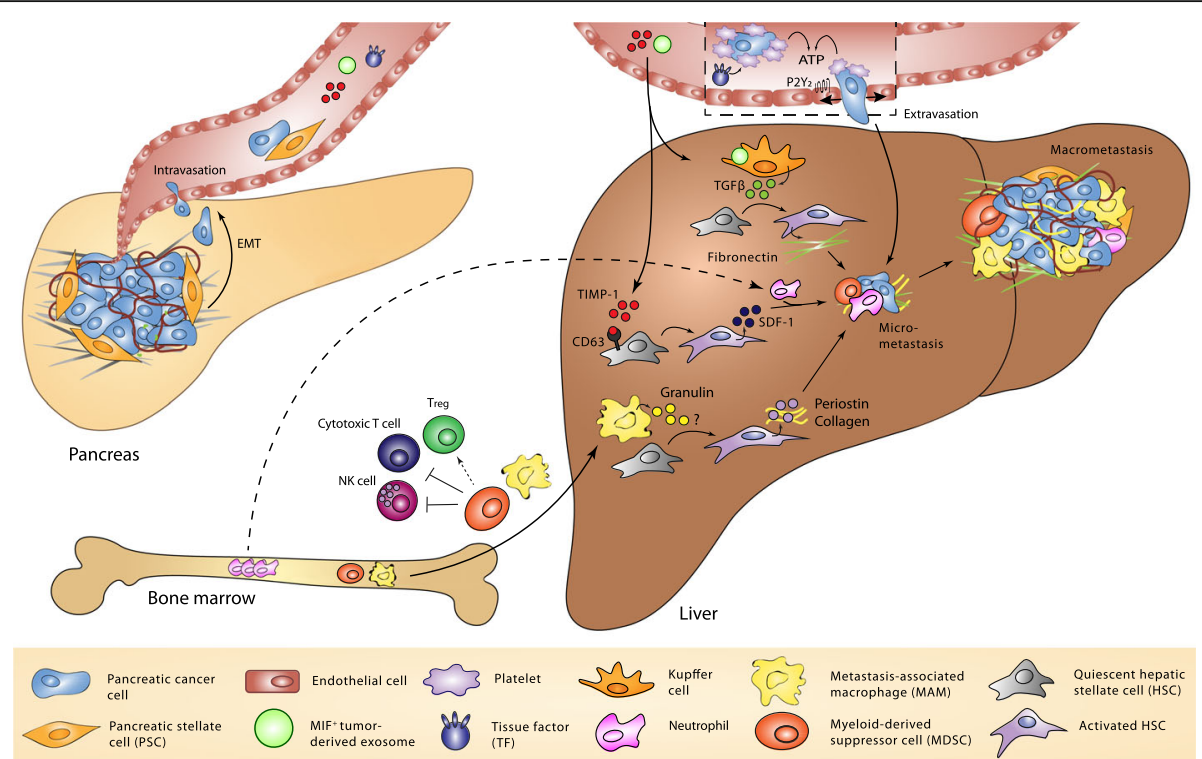

Fig. 1 Molecular and cellular events involved in PMN formation in PDAC. PSCs and matrix stiffness, part of the tumor-associated stroma, assist invasion and intravasation of pancreatic cancer cells, for example by inducing EMT. Meanwhile in the hepatic microenvironment, platelet activation and thrombus formation in response to microparticle-associated TF secreted by the primary tumor facilitates the arrest of disseminated pancreatic cancer cells. Opening of the endothelial barrier by activated platelets then facilitates their extravasation. Exosomes enriched in MIF shed by pancreatic cancer cells interact with Kupffer cells, which activate HSCs via the release of TGF $\beta$. The deposition of fibronectin by activated HSCs provides docking sites for metastasis-promoting bone marrow-derived cells such as macrophages and MDSCs. MDSCs impose immune tolerance by inhibiting NK cells and cytotoxic T cells and by promoting the development of Treg. Pancreatic cancer cell-derived TIMP-1 activates HSCs via its cognate receptor CD63 and induces the secretion of SDF-1, a chemoattractant for bone marrow-derived neutrophils. HSCs are also activated in response to MAM-derived granulin, which induces the production of periostin and collagen by HSCs. MAMs also inhibit anti-tumor immune responses by taking on an immunosuppressive M2 phenotype. PSC, pancreatic stellate cell; EMT, epithelial-to-mesenchymal transition; TF, tissue factor; MIF, macrophage inhibitory factor; HSC, hepatic stellate cell; TGF $\beta$, transforming growth factor $\beta$; MDSC, myeloid-derived suppressor cell; NK cell, natural killer cell; Treg, regulatory T cell; TIMP-1, tissue inhibitor of metalloproteinases-1; CD63, cluster of differentiation 63; SDF-1,

stromal-derived factor-1; MAM, metastasis-associated macrophage

induce their aggregation in favor of metastasis. Pancreatic tumor cells are capable of eliciting a remote pro-thrombotic state via the release of microparticles expressing TF into the systemic circulation [92-96]. TF is a prime initiator of the coagulation cascade; complex formation of TF with coagulation factor VII (FVII) triggers a series of reactions that culminate in the generation of thrombin and fibrinogen, which mediate platelet activation and aggregation into a fibrin clot [97]. The accumulation of platelets and the formation of thrombi could potentially be one of the initial hallmarks of PMN development [18]. Thrombus formation reduces shear stress at the vessel walls and interstitial fluid flow, so by inducing thrombosis in the hepatic vasculature, the primary tumor in the pancreas may remotely guide the arrest and subsequent extravasation of dissociated pancreatic tumor cells at the pre-metastatic site. Moreover, TF-induced platelet aggregates are also a major source of chemotactic signals and promote the homing of myeloid cells, for example granulocytes and monocytes/macrophages, to early metastatic niches [98, 99]. Myeloid cells are vital components of a developing PMN and will be discussed later in this review (see "Systemic immune cell recruitment"). TF-expressing microparticles shed from pancreatic tumor cells have also been shown to directly convert quiescent endothelial cells to a pro-adhesive and pro-inflammatory phenotype by upregulating the adhesion molecule E-selectin and inducing secretion of interleukin-8 (IL-8) [100]. Shortly after vascular arrest of pancreatic tumor cells, TF-activated platelets may further expedite their migration across the endothelium of hepatic blood vessels by secreting adenine nucleotides, which engage $\mathrm{P}_{2} \mathrm{Y}_{2}$ receptors on endothelial cells and instigate the opening of the endothelial barrier [101].

In addition, fibrinogen deposition and platelet activation induced by tumor-derived TF prompts the formation of platelet-tumor cell aggregates [102-104]. Besides further enhancing the arrest rate of tumor cells at distal vessels through multiple adhesion molecules, such aggregates may also physically shield pancreatic tumor cells from hematogenous shear forces and destruction by cytolytic natural killer (NK) cells.

\section{Tissue inhibitor of metalloproteinases-1: A double-edged sword in metastasis}

Given that proteolytic remodeling of the ECM is an indispensable aspect of systemic spread of tumor cells, 
MMPs have been widely regarded to serve pro-invasive and pro-metastatic functions [105]. However, the fact that a growing number of MMPs were found to have tumor-suppressive properties soon dampened enthusiasm for this notion. Perhaps even more paradoxical seemed to be the finding that an increase in systemic levels of TIMP-1, an endogenous inhibitor of a range of MMP family members, in fact renders the liver more susceptible to metastasis [106]. These and other observations indicated that the biology of MMPs and their respective inhibitors is far more intricate than previously anticipated, and that imbalances in the pervasive and highly connected interaction network they form part of can have unexpected but far-reaching consequences [107].

While TIMP-1 has long been known to be overexpressed in PDAC [108-112], it has only recently become apparent that TIMP-1 strongly influences tumor progression by triggering pro-metastatic conditioning of the liver. An initial hint at an important role for TIMP-1 in hepatic PMN formation has been the finding that elevated systemic levels of TIMP-1 promote the scattered infiltration of $\mathrm{T}$ lymphoma cells throughout the parenchyma of the liver [106, 107, 113]. Strikingly, TIMP-1 overexpression even redirects the spread of human fibrosarcoma cells from the lungs, where they typically form large metastatic foci, to the liver [106], implying that TIMP-1 specifically primes the liver microenvironment and thus dictates the pattern of metastasis in an organ-specific manner. This may be one reason why pancreatic cancer cells exhibit a predilection for metastasis to the liver.

Fundamental insights into how TIMP-1 prepares the liver microenvironment for the influx of tumor cells in PDAC have emerged only recently, largely owing to the elegant work of Grünwald and colleagues [114]. Perhaps the most intriguing aspect of their work is the finding that the process of hepatic PMN development in PDAC is set in motion exceptionally early. TIMP- 1 is already produced and secreted into the circulation by pancreatic premalignant lesions, and even patients with chronic pancreatitis, an inflammatory lesion from which PDAC may also develop, exhibit upregulated expression of TIMP-1. These observations suggest that a pro-metastatic niche is formed in the liver not only long before dissemination of pancreatic cancer cells, but already before (and in parallel with) primary tumor formation in the pancreas.

TIMP-1-induced conditioning of the liver for metastatic progression of PDAC is independent of its $\mathrm{N}$-terminal protease-inhibitory function. When pancreas-derived TIMP-1 reaches the liver via the circulation, its C-terminal domain serves a signaling role by binding to
CD63, a tetraspanin that is abundantly expressed on quiescent hepatic stellate cells (HSCs). The interaction of TIMP-1 with CD63 then initiates HSC activation. Since activated HSCs themselves are a major source of TIMP-1, this simultaneously generates an autoregulatory feedback loop that perpetuates HSC activation. Subsequent production and secretion of SDF-1 by activated HSCs establishes a chemotactic gradient along which neutrophils can infiltrate the liver via CXCR4. A previous study demonstrated that the TIMP-1-induced accumulation of neutrophils in the liver can be ascribed to enhanced granulopoiesis rather than direct mobilization or prolonged survival of mature neutrophils, as reflected by a 3-day delay in neutrophil recruitment and enrichment of myeloid progenitors in the bone marrow [115]. Neutrophils play an eminent role in PMN development as they actively promote ECM remodeling, angiogenesis and the chemoattraction of other inflammatory cells, each of which will subserve future pancreatic cancer cell colonization. Moreover, secretion of SDF-1 by activated HSCs has been demonstrated to attract colorectal carcinoma cells to the liver via CXCR4 [116]. TIMP-1-induced production of SDF-1 in the liver could potentially represent one mechanism directing the organotropic metastasis of pancreatic cancer cells, which also express high levels of CXCR4 [117]. Upregulation of TIMP-1 expression has also been identified as a potential resistance mechanism of pancreatic tumors against gemcitabine, and has been implicated in clonogenic survival of pancreatic cancer cells as well as vascular density [118].

In light of these findings, it is not surprising that high serum levels of TIMP-1 correlate with poor prognosis in patients with PDAC [119]. Plasma levels of TIMP-1 are higher in patients harbouring liver metastases compared to those who do not manifest metastatic disease [114]. Furthermore, Poruk and colleagues have demonstrated the utility of measuring systemic TIMP-1 levels as a diagnostic tool to distinguish early, resectable PDAC from healthy tissue and chronic pancreatitis [119]. Since chronic pancreatitis has been identified as a risk factor for PDAC [120], TIMP-1 warrants further attention as a potential biomarker to stratify patients with chronic pancreatitis based on their risk of pancreatic cancer.

\section{Pancreatic cancer cell-shed exosomes: Cell-free messengers of metastasis}

Beyond conventional signaling driven by soluble factors such as TIMP-1 and direct cell-cell contact, intercellular communication may also be mediated by more complex mechanisms involving small membrane-bound vesicles known as exosomes. Exosomes are a type of extracellular vesicle ranging from 30 to $150 \mathrm{~nm}$ in size that are actively shed by a multitude of cells, including malignant cells, and serve as vehicles for the horizontal transfer of 
a diverse array of proteins, lipids and nucleic acids [121]. Though exosomes are key mediators of intercellular signaling in normal physiology, it is rapidly becoming clear that they play a pivotal role in various cancer-related processes, particularly in the evolution of the PMN [122]. The secretion of exosomes enriched in functional biomolecules not only allows pancreatic cancer cells to shape the activity of adjacent cells in the tumor microenvironment, but also allows them to exploit distantly located cells in order to optimize the conditions for future metastatic seeding.

Costa-Silva et al. have recently defined several sequential exosome-mediated events that drive the development of the hepatic PMN in PDAC [121]. The relevance of these vesicular messengers in metastasis was corroborated by the finding that exosomes derived from the murine PDAC cell line PAN02 caused an increase in metastatic burden in the liver when injected into wildtype mice. Immunofluorescence and flow cytometric analysis showed that the vast majority of PDAC-derived exosomes selectively fuse with Kupffer cells, specialized macrophages that reside in the liver. Exosomes have been shown to be able to govern organotropic metastasis owing to specific repertoires of integrins expressed on their surface [123]. Exosomes shed by pancreatic cancer cells express the integrin $\alpha_{\mathrm{v}} \beta_{5}$ and thus interact specifically with Kupffer cells. Following adhesion, integrin uptake by Kupffer cells elicits upregulation of pro-migratory and pro-inflammatory S100P and S100A8 genes, suggesting that the interaction of exosomal integrins with recipient cells can trigger niche formation. In this way, PDAC-derived exosomes are able to direct the metastatic dissemination of pancreatic cancer cells to the liver.

One of the most highly upregulated genes following the fusion of PDAC-derived exosomes with Kupffer cells is the gene encoding TGF $\beta$, a well-established mediator of liver fibrosis [121]. TGF $\beta$ secreted by Kupffer cells acts directly on hepatic stellate cells (HSCs) to stimulate their activation, leading to enhanced deposition of the ECM component fibronectin. The fibronectin-rich ECM induced by PDAC-derived exosomes provides a docking site for metastatic tumor cells, as well as for macrophages and myeloid-derived suppressor cells mobilized from the bone marrow. Their arrest in pre-metastatic sites may be mediated by the presence of fibronectin-binding $\alpha_{4} \beta_{1}$ (VLA-4) and $\alpha_{4} \beta_{7}$ (LPAM-1) integrins expressed on their cell surface, as is the case for bone marrow-derived hematopoietic progenitors expressing vascular endothelial growth factor receptor 1 (VEGFR1) [19]. As discussed in a later section, the homing of bone marrow-derived cells to future metastatic sites is a centrally important aspect of PMN formation $[19,124]$. This is emphasized by the finding that depletion of fibronectin abolishes the pro-metastatic phenotype of PAN02 tumors in vivo [121]. Kupffer cells with upregulated expression of TGF $\beta$ can be detected remarkably early on during the development of PDAC, indicating that PDAC-derived exosomes play a pivotal role in the initial stages of PMN formation.

Costa-Silva et al. were able to identify macrophage migration inhibitory factor (MIF) as one of the molecular constituents of pancreatic cancer cell-derived exosomes that are integral to the construction of a permissive niche in the liver [121]. MIF was found to be expressed at high levels in PDAC-derived exosomes, and genetic ablation of MIF prevented the sequential events involved in liver PMN formation and pancreatic cancer metastasis in mice. This pro-inflammatory cytokine has previously been reported to contribute to pancreatic cancer aggressiveness by inducing EMT and reducing chemosensitivity in pancreatic cancer cell lines [125]. Given that increased expression of MIF in pancreatic exosomes is an early event which precedes liver metastasis in PDAC patients, MIF could potentially serve as a prognostic factor for metastatic risk [121]. The prognostic value of MIF in PDAC is further strengthened by the fact that elevated intratumoral levels of MIF mRNA correlate with poor survival in PDAC patients who have undergone surgery [125].

The increased awareness of the pervasive influence of exosomes on PDAC progression has sparked an enormous initiative to investigate their use as potential markers for the early detection of PDAC. Additionally, carbohydrate antigen 19-9 (CA 19-9), the only biomarker for PDAC that has been approved by the US Food and Drug Administration (FDA) to date, has proven to be a poor diagnostic tool [126]. The presence of elevated levels of CA 19-9 in non-malignant lesions such as peptic ulcers, chronic and acute pancreatitis and cirrhosis limits its utility as a biomarker [127-129]. Besides, CA 19-9 has inadequate sensitivity to detect early-stage PDAC, as a mere $50 \%$ of patients bearing pancreatic tumors less than $3 \mathrm{~cm}$ in size exhibit increased levels of CA 19-9 in the serum [129]. Table 1 displays several exosomal nucleic acids and proteins which have emerged as promising screening tools that may complement or replace CA $19-9$ and other current diagnostic modalities in the early identification of PDAC. As already demonstrated in the study by Costa-Silva et al. [121], exosomal contents may also be of prognostic relevance. Pancreatic cancer patients with distant metastatic disease were found to have higher levels of circulating glypican-1 (GPC1) ${ }^{+}$ exosomes than those with regional or no metastasis, and a substantial decrease in $\mathrm{GPC}^{+}$exosomes in the serum of PDAC patients following resection could predict improved overall and disease-specific survival [130]. Lastly, integrin expression profiles on circulating tumor exosomes may also be clinically relevant in predicting sites of future metastasis [123]. 
Table 1 Candidate exosomal biomarkers for the early detection of PDAC. miR, microRNA; CD44v6, cluster of differentiation variant 6; Tspan8, tetraspanin-8; EpCAM, epithelial cell adhesion molecule; CD104z, cluster of differentiation 104z; KRAS, Kirsten rat sarcoma virus; TP53, tumor protein p53

\begin{tabular}{|c|c|c|c|c|}
\hline Exosomal marker & Diagnostic value & Sensitivity & Specificity & Reference \\
\hline Glypican-1 (GPC1) & $\begin{array}{l}\text { GPC1 is a specific marker of cancer cell-derived exosomes } \\
\text { and exosomal GPC1 levels can distinguish patients with } \\
\text { early- and late-stage PDAC from healthy subjects and } \\
\text { patients with benign pancreatic lesions }\end{array}$ & $100 \%$ & $100 \%$ & [130] \\
\hline $\begin{array}{l}\text { High miR-10b, miR-21, miR-30c, } \\
\text { and miR-181a and low miR-let7a }\end{array}$ & $\begin{array}{l}\text { Differentiates pancreatic cancer cases from healthy } \\
\text { and chronic pancreatitis cases }\end{array}$ & $100 \%$ & $100 \%$ & [191] \\
\hline $\begin{array}{l}\text { CD44v6, Tspan8, EpCAM, } \\
\text { MET, CD104z, miR-1246, } \\
\text { miR-4644, miR-3976, miR-4306 }\end{array}$ & $\begin{array}{l}\text { Combined evaluation distinguishes patients with PDAC } \\
\text { from healthy subjects and patients with non-malignant disease }\end{array}$ & $100 \%$ & $80 \%$ & [192] \\
\hline miR-17-5-p & Discriminate between pancreatic cancer patients and healthy subjects & $72.7 \%$ & $92.6 \%$ & [193] \\
\hline miR-21 & Discriminate between pancreatic cancer patients and healthy subjects & $95.5 \%$ & $81.5 \%$ & [193] \\
\hline KRAS, TP53 & Exosomes contain genomic DNA with mutated KRAS and TP53 & - & - & [194] \\
\hline
\end{tabular}

\section{Systemic immune cell recruitment}

Beyond local changes such as an increase in vascular permeability, extensive remodeling of the ECM and manipulation of liver-resident cell types, the hepatic PMN in PDAC is also shaped by systemic changes pertaining to the immune system. Like the initial acquisition of invasive properties, intravasation and extravasation, continuous immune surveillance forms yet another rate-limiting step in the metastatic cascade that needs to be overcome to ensure successful metastatic outgrowth of incipient pancreatic cancer cells. As such, pancreatic cancer cells have evolved a myriad of mechanisms by which they can evade host immune responses. This section will cover ways in which the primary tumor in PDAC can mold pre-metastatic sites into immunosuppressive environments.

\section{Metastasis-associated macrophages create a supportive niche while warding off tumor-targeting immune cells by inducing fibrosis}

It is widely recognized that macrophages are actively recruited to the microenvironment of the primary tumor where they foster disease progression by promoting angiogenesis, migration and intravasation, and repressing anti-tumor immune responses [131, 132]. However, in recent years there has also been a growing appreciation for macrophages that populate distant (pre-)metastatic lesions and influence metastatic outcome at these sites. In a recent report, Nielsen et al. emphasized the significance of a distinct population of macrophages termed metastasis-associated macrophages (MAMs), which assist hepatic metastasis in PDAC by establishing a fibrotic microenvironment in the liver [133].

MAMs originate from inflammatory monocytes which undergo differentiation following recruitment from the bone marrow to the liver. The chemotactic factors that initiate their recruitment were not evaluated in the study by Nielsen et al., but potential candidates include $\mathrm{C}-\mathrm{C}$ motif chemokine ligang 2 (CCL2) and SDF-1 secreted by pancreatic cancer cells $[134,135]$. Once infiltrated in the liver, soluble factors derived from pancreatic cancer cells, for example colony stimulating factor-1 (CSF-1) [136], trigger MAMs to produce and secrete granulin, a glycoprotein previously implicated in the wound healing response and breast cancer as a potent activator of stromal fibroblasts $[137,138]$. Consistent with this role, macrophage-derived granulin instigates the activation of HSCs into myofibroblasts during liver metastasis in PDAC [133]. Unfortunately, our current mechanistic understanding of granulin-mediated HSC activation is limited due to conflicting reports with respect to the cognate cell-surface receptor for granulin. Nonetheless, granulin-activated HSCs are known to secrete high levels of ECM components, giving rise to a highly fibrotic environment. Besides collagen, one of the proteins particularly enriched in activated HSCs is periostin. This matricellular protein has previously been reported to encourage metastatic tumor development in colon cancer by augmenting cell survival via the Akt/PKB pathway [139]. In another study, breast cancer stem cells were shown to induce periostin expression in fibroblasts to aid metastatic colonization, presumably because deposition of periostin creates a supportive microenvironment which resembles that of the primary niche. Furthermore, periostin was found to support stem cell maintenance by facilitating Wnt signaling, thereby allowing breast cancer stem cells to initiate metastatic growth [140]. Nielsen et al. extended this work by demonstrating the requirement of periostin in the survival and growth of pancreatic cancer cells in vitro; a neutralizing antibody against periostin abolished the stimulatory effects of myofibroblast-conditioned medium on colony formation and proliferation of pancreatic cancer cells [133]. Notably, induction of periostin expression in activated HSCs was found to be strictly 
regulated by MAM-derived granulin, and depletion of granulin in KPC mice significantly diminished metastatic growth of pancreatic cancer cells. These findings further illustrate the central role of granulin and, consequently, periostin in PDAC metastasis.

Though this newly-described mechanism supporting liver metastasis in PDAC may seem reminiscent of the role of Kupffer cells, Nielsen et al. propose that these liver-resident macrophages and MAMs exert distinct functions within the temporal sequence of events [133]. While Kupffer cells are believed to predominantly facilitate initial seeding of pancreatic cancer cells, MAMs appear to be of greater relevance to subsequent cancer cell survival and growth. This may lead one to argue that MAMs are not involved in the early stages of PMN formation in the liver. In fact, it remains unclear from the study by Nielsen et al. whether MAM-induced activation of HSCs and concomitant fibrogenesis actually precede the arrival of pancreatic cancer cells in the liver. One methodological limitation of this study is the use of an experimental model of metastasis, which bypasses primary tumor development and hence fails to recapitulate the cardinal features of PMN formation [141]. In this regard, spontaneous models of metastasis are considered the gold standard. Further studies employing these models are therefore anticipated in order to gain a more comprehensive and spatiotemporal understanding of how MAMs assist colonization of pancreatic cancer cells in the liver.

Either way, the pro-metastatic role of granulin-secreting MAMs in vitro and in vivo is consistent with clinical observations in PDAC patients correlating inflammatory monocyte density in the peripheral blood with decreased patient survival [134]. Moreover, since granulin expression is already elevated in circulating inflammatory monocytes from KPC mice as well as from PDAC patients harboring liver metastases, it could have potential utility as a biomarker to predict metastasis in PDAC [133]. In this respect, it would be worth assessing whether granulin is also upregulated in inflammatory monocytes from patients with premalignant or inflammatory lesions. If this is the case, it would greatly increase the potential of granulin as a predictive biomarker.

In a recent extension of this work, Schmid's group uncovered an additional pro-tumorigenic function of MAMs that may causally link the abundance of inflammatory monocytes and decreased patient survival [135]. Macrophages in general display a high degree of plasticity [132]. In response to environmental stimuli, they can be polarized into a variety of phenotypes, with immune-stimulatory $\mathrm{M} 1$ and immunosuppressive M2 macrophages at either end of the spectrum. Initial seeding of pancreatic cancer cells and the development of micrometastases is accompanied by infiltration with tumoricidal cytotoxic T cells and M1-like MAMs, but upon progression to overt macrometastatic lesions, M2-like MAMs predominate, resulting in loss of $\mathrm{T}$ cell infiltration and effector function [135]. Since the efficacy of immune checkpoint blockade is heavily dependent on the ability of cytotoxic $\mathrm{T}$ cells to infiltrate into tumors, this rendered metastatic lesions less responsive to treatment with an anti-PD-1 monoclonal antibody. Functional experiments in PDAC mice revealed that CSF-1, which is abundantly expressed by metastatic pancreatic cancer cells, is able to expand the population of MAMs while driving their differentiation toward an M2-like phenotype.

CSF-1 also induces granulin expression by MAMs. Conceivably, the resulting desmoplastic reaction forms a physical barrier that precludes $\mathrm{T}$ cell infiltration into the metastatic site, thereby protecting pancreatic cancer cells from tumor-targeting immune responses. In line with this theory, residual cytotoxic $\mathrm{T}$ cells were noted to cluster primarily in peripheral regions of anti-PD-1-resistant tumors, in close proximity to activated HSCs [135]. Furthermore, the reduction in the number of cytotoxic $\mathrm{T}$ cells correlated with an accumulation of activated HSCs as well as enhanced collagen deposition. Interruption of metastasis-associated hepatic fibrosis by means of CSF-1 blockade or granulin depletion restored $\mathrm{T}$ cell infiltration and sensitized metastatic tumors to anti-PD-1 therapy in vivo. These data suggest that, via the release of CSF-1, metastatic pancreatic cancer cells are capable of undermining cytotoxic $\mathrm{T}$ cell-mediated immune surveillance by exploiting M2-polarized MAMs to construct a dense fibrotic stroma in the liver. Most importantly, they provide a strong rationale to explore the therapeutic benefit of immune checkpoint inhibitors in combination with compounds targeting granulin, and perhaps other pro-fibrotic factors, in advanced PDAC.

\section{Myeloid-derived suppressor cells: Imposing immune tolerance} Our understanding of tumor immunology and the importance thereof has expanded rapidly over the years and has spawned a renewed surge of interest in another population of bone marrow-derived cells termed myeloid-derived suppressor cells (MDSCs) [142]. MDSCs are a heterogeneous population of incompletely matured cells of myeloid origin endowed with potent immunosuppressive activity. In conditions of chronic inflammation and cancer, myelopoiesis is persistently stimulated which impairs the normal differentiation of granulocyte/monocyte precursors into mature granulocytes, monocytes or dendritic cells, leading to the accumulation of phenotypically similar but functionally distinct MDSCs in the peripheral blood, lymphoid organs and tumor-bearing tissues [142, 143]. Indeed, numerous studies have reported 
increased prevalence of circulating MDSCs in patients with various types of cancer, for example breast cancer [144, 145], non-small cell lung cancer [144], head and neck carcinoma [144], colorectal carcinoma [146, 147], renal cell carcinoma [148] and PDAC [145, 149, 150].

It is likely that MDSCs originally evolved as safeguards against uncontrolled immune responses that may damage healthy tissues [143]. Tumors, however, cunningly take advantage of this protective function and actively recruit MDSCs to permit tumor development and progression in the absence of tumor-specific immune attacks. Though a multitude of mechanisms have been described through which MDSCs perturb anti-tumor immunity, which immunosuppressive mechanism predominates seems to be partly influenced by the specific nature of the MDSC subset that is expanded. MDSCs can be broadly divided into granulocytic MDSCs and monocytic MDSCs. The prevalence of either of these two subsets differs depending on cancer type, though the currently available literature suggests that patients with PDAC accumulate both granulocytic and monocytic MDSCs in the peripheral blood and pancreatic tumor tissue [142, 151-153].

Granulocytic MDSCs release high levels of arginase I, an enzyme that reduces the availability of L-arginine in the microenvironment and in the circulation by hydrolyzing $\mathrm{L}$-arginine to $\mathrm{L}$-ornithine and urea $[151,154]$. L-arginine is required for $\mathrm{T}$ cell proliferation, cytokine production and expression of the $\zeta$ chain of the $\mathrm{T}$ cell co-receptor molecule $\mathrm{CD} 3(\mathrm{CD} 3 \zeta)$, so deficiency of this amino acid causes profound T cell dysfunction [148]. Simultaneously, arginase I directly subserves tumor growth since the newly generated supply of L-ornithine can be used for the synthesis of polyamines, compounds critically implicated in cell growth and survival $[155,156]$. The reactive oxygen species (ROS) hydrogen peroxide $\left(\mathrm{H}_{2} \mathrm{O}_{2}\right)$ derived from granulocytic MDSCs systemically suppresses $\mathrm{T}$ cell function in a similar manner [157]. In addition, ROS released by MDSCs mediate antigen-specific cytotoxic $\mathrm{T}$ cell tolerance by disrupting the integrity of the $\mathrm{T}$ cell receptor (TCR) complex [158]. MDSCs have the ability to take up foreign antigens, process them and present the resulting peptides to $\mathrm{T}$ cells. By mediating the nitration of tyrosine residues within the TCR complex and causing its dissociation, MDSC-derived ROS interfere with the interaction between MDSCs and cytotoxic T cells and prevent the induction of a $\mathrm{T}$ cell response against the presented peptide $[158,159]$. In a genetically engineered mouse model that spontaneously develops PDAC, tumor infiltration with MDSCs was found to be almost mutually exclusive with the loss of intratumoral effector $\mathrm{T}$ cells, indicative of a strong inhibition of $\mathrm{T}$ cell function and proliferation [160]. In agreement with this observation, targeted depletion of granulocytic MDSCs in KPC mice was shown to reestablish accumulation of activated cytotoxic $\mathrm{T}$ cells within the pancreatic tumor, accompanied by apoptosis of tumor cells and remodeling of the tumor stroma [161].

While $\mathrm{T}$ cells are their prime targets [143], MDSCs have also been reported to negatively regulate NK cell function by inducing NK cell anergy via membrane-bound TGF- $\beta 1$ $[162,163]$. Other studies have implicated MDSCs in the recruitment and maintenance of regulatory $\mathrm{T}$ cells $\left(\mathrm{T}_{\text {reg }}\right)$, a subpopulation of $\mathrm{T}$ cells renowned for their role in sustaining tolerance to self-antigens and in restricting excessive immune responses [160, 164]. Since many tumor antigens are in fact self-antigens, $\mathrm{T}_{\text {reg }}$ are also involved in limiting anti-tumor immune responses. Therefore it is not surprising that $\mathrm{T}_{\text {reg }}$ have been noted with increased prevalence in multiple forms of cancer, including PDAC [165]. Moreover, MDSCs have been shown to support neovascularization, providing further evidence that they also directly favor tumor progression. To this end, MDSCs may either secrete pro-angiogenic factors such as bombina variegate peptide 8 (Bv8) [166], VEGF or basic fibroblast growth factor (bFGF) [167], or liberate VEGF from the tumor-associated stroma by means of MMP9 $[168,169]$. MDSCs may even actively participate in tumor angiogenesis by differentiating into endothelial-like cells capable of embedding in the growing vascular endothelium [168].

While the association between MDSCs and the establishment of a PMN in the liver has not been thoroughly explored in PDAC, there is ample evidence to speculate that MDSCs indeed prepare the hepatic microenvironment for metastatic spread of pancreatic cancer cells by means of their pro-tumorigenic, immunosuppressive activities. Accumulation of MDSCs in the peripheral blood positively correlates with metastatic tumor burden in patients with PDAC and other types of cancer [145], and ablation of MDSCs by means of a neutralizing antibody profoundly suppresses metastasis [170]. Studies using a variety of tumor models, including a mouse model of PDAC, have revealed the capacity of MDSCs to home to and expand in the liver during pre-metastatic phases $[171,172]$. Importantly, depletion of liver MDSCs in mice harboring extrahepatic primary tumors was shown to dramatically reduce the frequency of liver metastases, indicating that these hepatic populations of MDSCs accelerate metastatic tumor growth in the liver [172]. Here, MDSCs were found to inhibit cytotoxic $\mathrm{T}$ cell activation, proliferation and cytotoxicity, as well as induce the development of $\mathrm{T}_{\text {reg. }}$. Furthermore, MDSCs within the liver have been demonstrated to interact with Kupffer cells and augment their expression of the negative $\mathrm{T}$ cell costimulatory molecule PD-L1 [171]. Notably, amplification of MDSCs can be detected in pancreatic tissue and in the peripheral blood of mice even before fully established primary tumors manifest in the pancreas [173]. Whether MDSCs also 
have a direct effect on circulating pancreatic cancer cells, however, has not been investigated.

The above findings suggest that early tumor-mediated recruitment of MDSCs to the future metastatic site in the liver ensures prosperous metastatic outgrowth by shielding incoming pancreatic cancer cells from tumor-specific immunosurveillance. Accordingly, numerous reports have identified distinct mechanisms through which pancreatic cancer cells elicit the accumulation of MDSCs. Keratinocyte-derived chemokine (KC), the murine homolog of human C-X-C motif ligand 1 (CXCL1), is a soluble factor that is already secreted by precursor lesions in a murine model of PDAC [172]. Ligation of $\mathrm{KC}$ to the KC receptor (CXCR2 in humans) is required for the previously described expansion of MDSCs in the livers of tumor-bearing mice. Mice deficient in the $\mathrm{KC}$ receptor showed a reduction in hepatic MDSC accumulation by more than $75 \%$, while primary tumor growth remained unaffected. In the liver, MDSCs themselves secrete high levels of $\mathrm{KC}$, among other regulatory and pro-inflammatory cytokines, so as to maintain the hepatic MDSC population. Consistent with these findings, Steele et al. [170] noted greatly upregulated expression of CXCL1 in KPC mice. Inhibition or genetic deletion of its receptor CXCR2 nearly completely abrogated metastasis in this model. Depletion of MDSCs, which are naturally a prominent source of CXCR2, had a similarly profound effect on metastasis. These data indicate that KC/CXCL1-dependent recruitment of MDSCs to the liver is indeed a pivotal event in the formation of a hospitable PMN.

Other soluble factors that have been associated with the recruitment of MDSCs by pancreatic cancer cells include granulocyte/macrophage colony-stimulating factor (GM-CSF) [174] and pancreatic adenocarcinoma upregulated factor (PAUF), a soluble protein previously implicated in pancreatic cancer metastasis [175]. PAUF has been suggested to attract MDSCs to tumor sites in an SDF-1-dependent manner by upregulating the expression of CXCR4 on MDSCs. In addition, the tumor-associated stroma may also interact with MDSCs to encourage their expansion and enhance their function; a recent study demonstrated the capability of PSCs to secrete several cytokines and chemokines that promoted the differentiation of peripheral blood mononuclear cells into immunosuppressive MDSCs, including IL-6, VEGF and macrophage colony-stimulating factor (M-CSF), and SDF-1 and monocyte chemoattractant protein-1 (MCP-1), respectively [176].

Interestingly, pancreatic cancer cell-derived exosomes have also been implicated in skewing the immune repertoire toward an immunosuppressive kind. Exosomes shed by pancreatic cancer cells can be internalized by
$\mathrm{CD}_{14}{ }^{+}$monocytes and impart a monocytic MDSC phenotype by downregulating HLA-DR expression and activating signal transducer and activator of transcription 3 (STAT3) signaling, with increased arginase I and ROS production as a result [153]. Another study reported that exosomes secreted by pancreatic cancer cells could expand both granulocytic and monocytic populations of MDSCs while lowering the number of dendritic cells, and proposed altered intracellular calcium fluxes as a potential mechanistic explanation [177]. The specific contents of pancreatic cancer cell-derived exosomes that govern the observed reprogramming of monocytes is presently unclear. Still, because exosomes have previously been shown to be employed by the primary tumor in PDAC to distantly prepare the liver for metastasis, these exciting discoveries provide further evidence supporting a role for MDSCs in the formation of a hepatic PMN in PDAC.

\section{Conclusions}

As highlighted in this review, the dynamic interplay between pancreatic cancer cells and their microenvironment strongly contributes to metastatic success. PSCs and matrix stiffness augment the invasive capacity of pancreatic cancer cells through a variety of mechanisms, in which the induction of EMT appears to be a recurrent theme. Two exciting emerging concepts warranting attention are the potential ability of PSCs to co-migrate with pancreatic cancer cells to distant organs to facilitate their seeding, and the ability of pancreatic cancer cells to co-opt stiffened collagen fibers as migratory tracks. However, metastasis is a highly complex process and goes far beyond mere dissociation of malignant cells from the primary tumor. Both in vitro and in vivo studies have clearly demonstrated that crosstalk among the primary tumor, platelets, HSCs, Kupffer cells and bone marrow-derived cells rigorously modulates the liver microenvironment such that it favors colonization by infiltrating pancreatic cancer cells. The early induction of PMN formation may begin to explain the capacity of pre-neoplastic pancreatic epithelial cells to enter the circulation and colonize distant organs [83] and, with that, the exceptionally aggressive nature of PDAC. This challenges the axiom that metastasis is a linear process involving the gradual evolution of a benign, local lesion into a malignant tumor [178], and lends support to a parallel progression model [179].

Accumulating evidence supports a link between TF-induced platelet aggregation and PMN formation. Strikingly, even though high intratumoral TF expression has been identified as an adverse prognostic factor in PDAC [180, 181], clinical studies so far have failed to find a correlation between TF expression and hematogenous metastasis [181]. This is disconcerting because it has 
previously been demonstrated that inhibition of TF completely abolished hematogenous metastatic spread in a murine model of PDAC [182]. In another study, increased microparticle-associated TF activity in the plasma of pancreatic cancer patients was only present in those with metastatic, non-resectable tumors [94]. Further analyses are required to reconcile these discrepancies regarding the clinicopathological significance of TF.

A largely unexplored question in this field is what determines the organ specificity of TIMP-1 in PMN development. While TIMP-1 is known to promote liver metastasis, it actually reduces metastasis to the lungs [106]. Similarly, various studies have documented organ-specific promotion of metastasis upon inhibition or overexpression of proteases or protease families [183-185]. Additional studies dissecting the complexities of the pro-metastatic effects of TIMP-1 are therefore highly anticipated. Still, the recent discoveries implicating TIMP-1 in the evolution of the hepatic PMN could potentially open new avenues from a therapeutic standpoint. If rising plasma levels of TIMP-1 indeed represent a reliable biomarker of metastatic progression in PDAC, they might provide a window of opportunity for intervention with, or even prevention of, liver metastasis. However attractive this approach might seem theoretically, the therapeutic targeting of TIMP-1 would also entail important mechanistic issues. As described earlier, excessive proteolytic activity can remodel the ECM in favor of invasion. Straightforward inhibition of TIMP-1 might in fact advance the spread of pancreatic cancer cells as a consequence of reduced protease inhibition. The identification or development of a compound that abrogates the ability of TIMP-1 to interact with CD63 while preserving its protease-inhibitory function may overcome this issue. Clearly, further work is required in this area before clinical applications can be considered.

Exosomes are emerging as key players in intercellular communication and niche formation in PDAC. MIF has proven to be essential in this process, but requires further validation as a prognostic biomarker, which calls for clinical studies that link elevated levels of MIF in patients with chronic pancreatitis to the development of liver metastases. Undoubtedly, exosomes impact pancreatic cancer metastasis in ways that reach beyond MIF-dependent interactions. Proteomic and gene ontology enrichment analyses of exosomal cargo revealed that many proteins enriched in pancreatic cancer exosomes are functionally involved in metabolic processes [186], suggesting that exosome-mediated metabolic reprogramming may represent an additional aspect of PMN formation. Given the present paucity of reliable diagnostic biomarkers of PDAC, efforts have been made to harness the potential of exosomes to aid the early detection of pancreatic tumors. Exosomes are abundant and stable, and their isolation is cheaper and less invasive than current diagnostic methods. Sadly, the present heterogeneity in techniques used to isolate exosomes curtails the clinical relevance of laboratory-based studies of exosomes [187]. Isolation methods will need to be standardized and streamlined to allow high-throughput purification and analysis of exosomes in the clinic. Large-scale prospective studies are also required to validate candidate exosomal biomarkers in a population-screening context and to confirm that early detection of PDAC indeed improves the likelihood of cure, but such studies are thwarted by the limited availability of biospecimens from patients with early-stage disease caused by the current lack of early detection markers [188]. Evidently, the road to successful implementation of exosomes as diagnostic biomarkers will likely be a long one.

Suppression of the immune system also proved integral to the evolution of the PMN in the liver, yet many gaps remain in our mechanistic understanding of the contribution of MAMs and MDSCs to PMN formation. The functional role of MAM-derived periostin in PDAC metastasis and the tumor-secreted factors that regulate MDSC activity remain speculative. Still, the preliminary insights discussed here are hoped to serve as building blocks for further research into the interaction between pancreatic cancer cells and immunosuppressive cells.

Lastly, the studies reviewed here are limited by the use of different preclinical models to examine PMN formation, some of which fail to exemplify the complex cellular and molecular architecture of the PMN $[189,190]$. The development of in vivo models that recapitulate PMN formation more faithfully is an important future direction in the area of PDAC metastasis, as they will allow researchers to further dissect the tumor-host interactions that regulate the evolution of the hepatic niche in PDAC, as well as the spatial and temporal organization of these interactions. Notwithstanding the above shortcomings, the novel insights discussed in this review hold promise to help surmount the current lack of therapeutic success in PDAC.

\footnotetext{
Abbreviations

bFGF: basic fibroblast growth factor; Bv8: Bombina variegate peptide 8; CA 19-9: Carbohydrate antigen 19-9; CAF: Cancer-associated fibroblast; CCL2: CC motif chemokine ligand 2; COX-2: Cyclooxygenase 2; CSF-1: Colony stimulating factor-1; CXCL1: C-X-C motif ligand 1; CXCR4: C-X-C chemokine receptor 4; ECM: Extracellular matrix; EMT: Epithelial-to-mesenchymal transition; FAK: Focal adhesion kinase; FDA: Food and Drug Administration; FGF2: Fibroblast growth factor 2; FGFR1: Fibroblast growth factor receptor 1; FVII: Coagulation factor VIl; GM-CSF: Granulocyte/macrophage colonystimulating factor; GPC1: Glypican 1; HAS2: Hyaluronan synthase 2; hPSC: Human pancreatic stellate cell; HSC: Hepatic stellate cell; IL: Interleukin; KC: Keratinocyte-derived chemokine; MAM: Metastasis-associated macrophage; MCP-1: Monocyte chemoattractant protein-1; MCSF: Macrophage colony-stimulating factor; MDSC: Myeloid-derived suppressor cell; MIF: Macrophage migration inhibitory factor; MMP: Matrix metalloproteinase; NK: Natural killer; PAUF: Pancreatic adenocarcinoma upregulated factor; PD-1: Programmed cell death protein 1; PDAC: Pancreatic ductal adenocarcinoma; PDGF: Platelet-derived growth factor; PD-

L1: Programmed death ligand 1; PMN: Pre-metastatic niche; PSC: Pancreatic
} 
stellate cell; PTGS2: Prostaglandin-endoperoxide synthase 2; ROS: Reactive oxygen species; SDF-1: Stromal-derived factor-1; STAT3: Signal transducer and activator of transcription 3; TCR: T cell receptor; TF: Tissue factor; TGF $\beta 1$ : Transforming growth factor $\beta 1$; TIMP-1: Tissue inhibitor of metalloproteinases-1; $T_{\text {reg: }}$ : Regulatory $T$ cell; VEGF: Vascular endothelial growth factor; VEGFR1: Vascular endothelial growth factor receptor 1: aSMA: a-smooth muscle actin

\section{Funding}

This work was supported by a KWF Dutch Cancer Society grant to MFB (UVA 2013-5932). This funding body had no role in the writing of this manuscript.

\section{Availability of data and materials}

Data sharing is not applicable to this article as no datasets were generated or analysed during the current study.

\section{Authors' contributions}

DSH drafted the first version of the manuscript. MFB supervised the process. Both authors have critically reviewed and approved the manuscript.

\section{Ethics approval and consent to participate}

Not applicable.

\section{Competing interests}

The authors declare that they have no competing interests.

\section{Publisher's Note}

Springer Nature remains neutral with regard to jurisdictional claims in published maps and institutional affiliations.

Received: 13 March 2018 Accepted: 31 May 2018

Published online: 14 June 2018

\section{References}

1. Siegel RL, Miller KD, Jemal A. Cancer statistics, 2017. CA-Cancer J Clin. 2017:67:7-30

2. Åkerberg D, Ansari D, Andersson R, Tingstedt B. The effects of surgical exploration on survival of unresectable pancreatic carcinoma: a retrospective case-control study. J Biomed Sci Eng. 2017;10:1-9.

3. Paulson AS, Tran Cao HS, Tempero MA, Lowy AM. Therapeutic advances in pancreatic cancer. Gastroenterology. 2013;144:1316-26.

4. Garrido-Laguna I, Hidalgo M. Pancreatic cancer: from state-of-the-art treatments to promising novel therapies. Nat Rev Clin Oncol. 2015:12:319-34.

5. Almoguera C, Shibata D, Forrester K, Martin J, Arnheim N, Perucho M. Most human carcinomas of the exocrine pancreas contain mutant c-K-ras genes. Cell. 1988;53:549-54.

6. Schutte M, Hruban RH, Geradts J, Maynard R, Hilgers W, Rabindran SK, Moskaluk CA, Hahn SA, Schwarte-Waldhoff I, Schmiegel W, et al. Abrogation of the $\mathrm{Rb} / \mathrm{p} 16$ tumor-suppressive pathway in virtually all pancreatic carcinomas. Cancer Res. 1997;57:15.

7. Hruban RH, Goggins M, Parsons J, Kern SE. Progression model for pancreatic cancer. Clin Cancer Res. 2000:6:8.

8. Hingorani SR, Wang L, Multani AS, Combs C, Deramaudt TB, Hruban RH, Rustgi AK, Chang S, Tuveson DA. Trp53R127H and KrasG12D cooperate to promote chromosomal instability and widely metastatic pancreatic ductal adenocarcinoma in mice. Cancer Cell. 2005;7:469-83.

9. Li C, Heidt DG, Dalerba P, Burant CF, Zhang L, Adsay V, Wicha M, Clarke MF, Simeone DM. Identification of pancreatic cancer stem cells. Cancer Res. 2007;67:1030-7.

10. Jones S, Zhang X, Parsons DW, Lin JC, Leary RJ. Core signaling pathways in human pancreatic cancers revealed by global genomic analyses. Science. 2008;321:1801-6

11. Burris HA 3rd, Moore MJ, Andersen J, Green MR, Rothenberg ML, Modiano MR, Cripps MC, Portenoy RK, Storniolo AM, Tarassoff P, et al. Improvements in survival and clinical benefit with gemcitabine as first-line therapy for patients with advanced pancreas cancer: a randomized trial. J Clin Oncol. 1997:15:2403-13

12. Von Hoff DD, Ervin T, Arena FP, Chiorean G, Infante J, Moore M, Seay T, Tjulandin SA, Ma WW, Saleh MN, et al. Increased survival in pancreatic cancer with nab-paclitaxel plus gemcitabine. N Engl J Med. 2013;369:1691-703.
13. Neoptolemos JP, Palmer DH, Ghaneh P, Psarelli EE, Valle J, Halloran CM, Faluyi O, O'Reilly DA, Cunningham D, Wadsley J, et al. Comparison of adjuvant gemcitabine and capecitabine with gemcitabine monotherapy in patients with resected pancreatic cancer (ESPAC-4): a multicentre, openlabel, randomised, phase 3 trial. Lancet. 2017;389:1011-24.

14. Paget $\mathrm{S}$. The distribution of secondary growths in cancer of the breast. Lancet. 1889:133:571-3.

15. lacobuzio-Donahue CA, Fu B, Yachida S, Luo M, Abe H, Henderson CM, Vilardell F, Wang Z, Keller JW, Banerjee P, et al. DCP4 gene status of the primary carcinoma correlates with patterns of failure in patients with pancreatic cancer. J Clin Oncol. 2009;27:1806-13.

16. Yachida S, White CM, Naito Y, Zhong Y, Brosnan JA, Macgregor-Das AM, Morgan RA, Saunders T, Laheru DA, Herman JM, et al. Clinical significance of the genetic landscape of pancreatic cancer and implications for identification of potential long-term survivors. Clin Cancer Res. 2012;18:6339-47.

17. Lyden D, Welch DR, Psaila B, editors. Cancer metastasis: biologic basis and therapeutics. Cambridge and New York: Cambridge University Press; 2011.

18. Peinado $H$, Zhang $H$, Matei IR, Costa-Silva B, Hoshino A, Rodrigues $G$, Psaila B, Kaplan RN, Bromberg JF, Kang Y, et al. Pre-metastatic niches: organspecific homes for metastases. Nat Rev. 2017:17:302-17.

19. Kaplan RN, Riba RD, Zacharoulis S, Bramley AH, Vincent L, Costa C, MacDonald DD, Jin DK, Shido K, Kerns SA, et al. VEGFR1-positive haematopoietic bone marrow progenitors initiate the pre-metastatic niche. Nature. 2005;438:820-7.

20. Hiratsuka S, Watanabe A, Aburatani H, Maru Y. Tumour-mediated upregulation of chemoattractants and recruitment of myeloid cells predetermines lung metastasis. Nat Cell Biol. 2006:8:1369-75.

21. Hiratsuka S, Watanabe A, Sakurai Y, Akashi-Takamura S, Ishibashi S, Miyake K, Shibuya M, Akira S, Aburatani H, Maru Y. The S100A8-serum amyloid A3TLR4 paracrine cascade establishes a pre-metastatic phase. Nat Cell Biol. 2008:10:1349-55.

22. Steeg PS. Tumor metastasis: mechanistic insights and clinical challenges. Nat Med. 2006:12:895-904.

23. Beuran M, Negoi I, Paun S, Ion AD, Bleotu C, Negoi Rl, Hostiuc S. The epithelial to mesenchymal transition in pancreatic cancer: a systematic review. Pancreatology. 2015;15:217-25.

24. Hay ED. An overview of epithelio-mesenchymal transformation. Acta Anat. 1995:154:8-20.

25. Maier HJ, Wirth T, Beug H. Epithelial-mesenchymal transition in pancreatic carcinoma. Cancers (Basel). 2010;2:2058-83.

26. Kalluri R, Weinberg RA. The basics of epithelial-mesenchymal transition. J Clin Invest. 2009:119:1420-8.

27. Zheng X, Carstens JL, Kim J, Scheible M, Kaye J, Sugimoto H, Wu C, LeBleu VS, Kalluri R. EMT program is dispensable for metastasis but induces chemoresistance in pancreatic cancer. Nature. 2015;527:525-30.

28. Aiello NM, Brabletz T, Kang Y, Nieto MA, Weinberg RA, Stanger BZ. Upholding a role for EMT in pancreatic cancer metastasis. Nature. 2017;547:E7-8.

29. Krebs AM, Mitschke J, Losada ML, Schmalhofer O, Boerries M, Busch H, Boettcher M, Mougiakakos D, Reichardt W, Bronsert P, et al. The EMTactivator Zeb1 is a key factor for cell plasticity and promotes metastasis in pancreatic cancer. Nat Cell Biol. 2017;19:518-42.

30. Arumugam $T$, Ramachandran $V$, Fournier KF, Wang H, Marquis $L$, Abbruzzese JL, Gallick GE, Logsdon CD, McConkey DJ, Choi W. Epithelial to mesenchymal transition contributes to drug resistance in pancreatic cancer. Cancer Res. 2009:69:5820-8.

31. Rucki AA, Zheng L. Pancreatic cancer stroma: understanding biology leads to new therapeutic strategies. World J Gastroenterol. 2014;20: 2237-46.

32. Erkan M, Michalski CW, Rieder S, Reiser-Erkan C, Abiatari I, Kolb A, Giese NA, Esposito I, Friess $\mathrm{H}$, Kleeff J. The activated stroma index is a novel and independent prognostic marker in pancreatic ductal adenocarcinoma. Clin Gastroenterol Hepatol. 2008;6:1155-61.

33. Wilson JS, Pirola RC, Apte MV. Stars and stripes in pancreatic cancer: role of stellate cells and stroma in cancer progression. Front Physiol. 2014;5:52.

34. Hwang RF, Moore T, Arumugam T, Ramachandran V, Amos KD, Rivera A, B, Evans DB, Logsdon CD. Cancer-associated stromal fibroblasts promote pancreatic tumor progression. Cancer Res. 2008;68:918-26.

35. Mantoni TS, Lunardi S, Al-Assar O, Masamune A, Brunner TB. Pancreatic stellate cells radioprotect pancreatic cancer cells through $\beta 1$-integrin signaling. Cancer Res. 2011;71:3453-8. 
36. Gao Z, Wang X, Wu K, Zhao Y, Hu G. Pancreatic stellate cells increase the invasion of human pancreatic cancer cells through the stromal cell-derived factor-1/CXCR4 axis. Pancreatology. 2010;10:186-93.

37. Cheng X, Kohi S, Koga A, Hirata K, Sato N. Hyaluronan stimulates pancreatic cancer cell motility. Oncotarget. 2016;7:4829-40.

38. Phillips P. Pancreatic stellate cells and fibrosis. In: Grippo PJ, Munshi HG, editors. Pancreatic Cancer and tumor microenvironment. Trivandrum: Transworld Research Network; 2012.

39. Olive KP, Jacobetz MA, Davidson CJ, Gopinathan A, McIntyre D, Honess D, Madhu B, Goldgraben MA, Caldwell ME, Allard D. Inhibition of hedgehog signaling enhances delivery of chemotherapy in a mouse model of pancreatic cancer. Science. 2009:324:1457-61.

40. Jacobetz MA, Chan DS, Neesse A, Bapiro TE, Cook N, Frese KK, Feig C, Nakagawa T, Caldwell ME, Zecchini HI. Hyaluronan impairs vascular function and drug delivery in an mouse model of pancreatic cancer Gut. 2013;62:112-20.

41. Al-Assar O, Demiciorglu F, Lunardi S, Gaspar-Carvalho MM, McKenna WG Muschel RM, Brunner TB. Contextual regulation of pancreatic cancer stem cell phenotype and radioresistance by pancreatic stellate cells. Radiother Oncol. 2014;11:243-51.

42. Apte MV, Park S, Phillips PA, Santucci N, Goldstein D, Kumar RK, Ramm GA Buchler M, Friess H, McCarroll JA. Desmoplastic reaction in pancreatic cancer: role of pancreatic stellate cells. Pancreas. 2004;29:179-87.

43. Vonlaufen A, Joshi S, Qu C, Phillips PA, Xu Z, Parker NR, Toi CS, Pirola RC, Wilson JS, Goldstein D, Apte MV. Pancreatic stellate cells: partners in crime with pancreatic cancer cells. Cancer Res. 2008;68:2085-93.

44. Phillips PA, Wu MJ, Kumar RK, Doherty E, McCarroll JA, Park S, Pirola RC, Wilson JS, Apte MV. Cell migration: a novel aspect of pancreatic stellate cell biology. Gut. 2003;52:677-82.

45. Bachem MG, Schünemann M, Ramadani M, Siech M, Beger H, Buck A, Zhou S, Schmid-Kotsas A, Adler G. Pancreatic carcinoma cells induce fibrosis by stimulating proliferation and matrix synthesis of stellate cells. Gastroenterology. 2005;128:907-21.

46. Hessmann E, Patzak MS, Klein L, Chen N, Kari V, Ramu I, Bapiro TE, Frese KK, Gopinathan A, Richards FM, et al. Fibroblast drug scavenging increases intratumoural gemcitabine accumulation in murine pancreas cancer. Gut. 2018;67:497-507.

47. Kikuta K, Masamune A, Watanabe T, Ariga H, Itoh H, Hamada S, Satoh K, Egawa S, Unno M, Shimosegawa T. Pancreatic stellate cells promote epithelial-mesenchymal transition in pancreatic cancer cells. Biochem Biophys Res Commun. 2010;403:380-4.

48. Qian D, Lu Z, Xu Q, Wu P, Tian L, Zhao L, Cai B, Yin J, Wu Y, StaveleyO'Carroll KF. Galectin-1-driven upregulation of SDF-1 in pancreatic stellate cells promotes pancreatic cancer metastasis. Cancer Lett. 2017;397:43-51.

49. Li X, Ma Q, Xu Q, Liu H, Lei J, Duan W, Bhat K, Wang F, Wu E, Wang Z. SDF1/CXCR4 signaling induces pancreatic cancer cell invasion and epithelialmesenchymal transition in vitro through noncanonical activation of hedgehog pathway. Cancer Lett. 2012;322:169-76.

50. Sato N, Maehara N, Goggins M. Gene expression profiling of tumor-stromal interactions between pancreatic cancer cells and stromal fibroblasts. Cancer Res. 2004;64:6950-6.

51. Tsujii M, Kawano S, DuBois RN. Cyclooxygenase-2 expression in human colon cancer cells increases metastatic potential. P Natl Acad Sci USA. 1997; 94:3336-40.

52. Gialeli C, Theocharis AD, Karamanos NK. Roles of matrix metalloproteinases in cancer progression and their pharmacological targeting. FEBS J. 2010;278: $16-27$.

53. Okami J, Nakamori S, Hiraoka N, Tsujie M, Hayashi N, Yamamoto H, Fujiwara Y, Nagano H, Dono K, Umeshita K, et al. Suppression of pancreatic cancer cell invasion by a cyclooxygenase-2-specific inhibitor. Clin Exp Metastas. 2003;20:577-84.

54. Wei D, Wang L, He Y, Xiong HQ, Abbruzzese JL, Xie K. Celecoxib inhibits vascular endothelial growth factor expression in and reduces angiogenesis and metastasis of human pancreatic cancer via suppression of Sp1 transcription factor activity. Cancer Res. 2004;64:2030-8.

55. Theocharis AD, Tsara ME, Papageorgacopoulou N, Karavias DD, Theocharis DA. Pancreatic carcinoma is characterized by elevated content of hyaluronan and chondroitin sulfate with altered disaccharide composition. Biochim Biophys Act. 2000;1502:201-6.

56. Itano N, Atsumi F, Sawai T, Yamada Y, Miyaishi O, Senga T, Hamaguchi M, Kimata K. Abnormal accumulation of hyaluronan matrix diminishes contact inhibition of cell growth and promotes cell migration. P Natl Acad Sci USA. 2002;99:3609-14.

57. Kim HR, Wheeler MA, Wilson CM, lida J, Eng D. Hyaluronan facilitates invasion of colon carcinoma cells in vitro via interaction with CD44. Cancer Res. 2004;64:4569-76.

58. Liu N, Gao F, Han Z, Xu X, Underhill CB, Zhang L. Hyaluronan synthase 3 overexpression promotes the growth of TSU prostate cancer cells. Cancer Res. 2001;61:5207-17.

59. Scaife CL, Shea JE, Dai Q, Firpo MA, Prestwich GD, Mulvihill SJ. Synthetic extracellular matrix enhances tumor growth and metastasis in an orthotopic mouse model of pancreatic adenocarcinoma. J Gastrointest Surg. 2008;12: 1074-80.

60. Camenisch TD, Spicer AP, Brehm-Gibson T, Biesterfeldt J, Augustine ML, Calabro A Jr, Kubalak S, Klewer SE, McDonald JA. Disruption of hyaluronan synthase-2 abrogates normal cardiac morphogenesis and hyaluronanmediated transformation of epithelium to mesenchyme. J Clin Invest. 2000; 106:349-60.

61. Zoltan-Jones A, Huang L, Ghatak S, Toole BP. Elevated hyaluronan production induces mesenchymal and transformed properties in epithelial cells. J Biol Chem. 2003;278:45801-10.

62. Kultti A, Zhoa C, Singha NC, Zimmerman S, Osgood RJ, Symons R, Jiang P, Li X, Thompson CB, Infante JR, et al. Accumulation of extracellular hyaluronan by hyaluronan synthase 3 promotes tumor growth and modulates the pancreatic cancer microenvironment. Biomed Res Int. 2014; 2014:817613.

63. Hanahan D, Weinberg RA. Hallmarks of cancer: the next generation. Cell. 2010;144:646-74.

64. Vonlaufen A, Phillips PA, Xu Z, Goldstein D, Pirola RC, Wilson JS, Apte MV. Pancreatic stellate cells and pancreatic cancer cells: an unholy alliance. Cancer Res. 2008;68:7707-10.

65. Masamune A, Kikuta K, Watanabe T, Satoh K, Shimosegawa T. Pancreatic stellate cells induce angiogenesis. Pancreas. 2009;38:483.

66. Xu Z, Vonlaufen A, Phillips PA, Fiala-Beer E, Zhang X, Yang L, Biankin AV, Goldstein D, Pirola RC, Wilson JS, et al. Role of pancreatic stellate cells in pancreatic cancer metastasis. Am J Pathol. 2010;177:2585-96.

67. Masamune A, Kikuta K, Watanabe T, Satoh K, Hirota M, Shimosegawa T. Hypoxia stimulates pancreatic stellate cells to induce fibrosis and angiogenesis in pancreatic cancer. Am J Phys. 2008;295:G709-17.

68. Erkan M, Reiser-Erkan C, Michalski CW, Deucker S, Sauliunaite D, Streit S, Esposito I, Friess H, Kleeff J. Cancer-stellate cell interactions perpetuate the hypoxia-fibrosis cycle in pancreatic ductal adenocarcinoma. Neoplasia. 2009; 11:497-508.

69. Suetsugu A, Snyder CS, Moriwaki H, Saji S, Bouvet M, Hoffman RM. Imaging the interaction of pancreatic cancer and stellate cells in the tumor microenvironment during metastasis. Anticancer Res. 2015;35:2545-51.

70. Coleman SJ, Chioni AM, Ghallab M, Anderson RK, Lemoine NR, Kocher HM, Grose RP. Nuclear translocation of FGFR1 and FGF2 in pancreatic stellate cells facilitates pancreatic cancer cell invasion. EMBO Mol Med. 2014;6:467-81.

71. Fang M, Yuan J, Peng C, Li Y. Collagen as a double-edged sword in tumor progression. Tumour Biol. 2014;5:2871-82.

72. Paszek MJ, Zahir N, Johnson KR, Lakins JN, Rozenberg Gl, et al. Tensiona homeostasis and the malignant phenotype. Cancer Cell. 2005:8:241-54.

73. Wei SC, Fattet L, Tsai JH, Guo Y, Pai VH, Majeski HE, Chen AC, Sah RL, Taylor SS, Engler AJ, et al. Matrix stiffness drives epithelial-mesenchymal transition and tumour metastasis through a TWIST1-G3BP2 mechanotransduction pathway. Nat Cell Biol. 2015;17:678-88.

74. Rice AJ, Cortes E, Lachowski D, Cheung BCH, Karim SA, Morton JP, Del Río Hernández A. Matrix stiffness induces epithelial-mesenchymal transition and promotes chemoresistance in pancreatic cancer cells. Oncogene. 2017;6:e352.

75. Haage A, Schneider IC. Cellular contractility and extracellular matrix stiffness regulate matrix metalloproteinase activity in pancreatic cancer cells. FASEB J. 2014;28:3589-99.

76. Koenig A, Mueller C, Hasel C, Adler G, Menke A. Collagen type I induces disruption of E-cadherin-mediated cell-cell contacts and promotes proliferation of pancreatic carcinoma cells. Cancer Res. 2006;66:4662-71.

77. Shintani Y, Hollingsworth MA, Wheelock MJ, Johnson KR. Collagen I promotes metastasis in pancreatic cancer by activating c-Jun $\mathrm{NH}(2)$-terminal kinase 1 and up-regulating N-cadherin expression. Cancer Res. 2006;66:11745-53.

78. Imamichi Y, König A, Gress T, Menke A. Collagen type I-induced Smadinteracting protein 1 expression downregulates E-cadherin in pancreatic cancer. Oncogene. 2007;25:2381-5. 
79. Wang W, Wyckoff JB, Centonze Frohlich V, Oleynikov Y, Hüttelmaier S, Zavadil J, Cermak L, Bottinger EP, Singer RH, White JG, et al. Single cell behavior in metastatic primary mammary tumors correlated with gene expression patterns revealed by molecular profiling. Cancer Res. 2002;62:6278-88.

80. Lu J, Zhou S, Siech M, Habisch H, Seufferlein T, Bachem MG. Pancreatic stellate cells promote hapto-migration of cancer cells through collagen Imediated signalling pathway. Brit J Cancer. 2014;110:409-20.

81. Drifka CR, Tod J, Loeffler AG, Liu Y, Thomas GJ, Eliceiri KW, Kao WJ. Periductal stromal collagen topology of pancreatic ductal adenocarcinoma differs from that of normal and chronic pancreatitis. Modern Pathol. 2015;28:1470-80.

82. Beerling E, Oosterom I, Voest E, Lolkema M, Van Rheenen J. Intravital characterization of tumor cell migration in pancreatic cancer. Intravital. 2016:5:e1261773.

83. Rhim AD, Mirek ET, Aiello NM, Maitra A, Bailey JM, McAllister F, Reichert M, Beatty GL, Rustgi AK, Vonderheide $\mathrm{RH}$, et al. EMT and dissemination precede pancreatic tumor formation. Cell. 2012;148:349-61.

84. Chambers AF, Naumov GN, Varghese HJ, Nadkarni KV, Mac Donald IC, Groom AC. Critical steps in hematogenous metastasis: an overview. Surg Oncol Clin N Am. 2001;10:243-55.

85. Khorana AA, Fine RL. Pancreatic cancer and thromboembolic disease. Lancet Oncol. 2004;5:655-63.

86. Tzanakakis GN, Agarwal KC, Veronikis DK, Vezeridis MP. Effects of antiplatelet agents alone or in combinations on platelet aggregation and on liver metastases from a human pancreatic adenocarcinoma in the nude mouse. J Surg Oncol. 1991;48:45-50.

87. Brown KM, Domin C, Aranha GV, Yong S, Shoup M. Increased preoperative platelet count is associated with decreased survival after resection for adenocarcinoma of the pancreas. Am J Surg. 2005;189:278-82.

88. Wang H, Gao J, Bai M, Liu R, Li H, Deng T, Zhou L, Han R, Ge S, Huang D, et al. The pretreatment platelet and plasma fibrinogen level correlate with tumor progression and metastasis in patients with pancreatic cancer. Platelets. 2014;25:382-7.

89. Mezouar S, Darbousset R, Dignat-George F, Panicot-Dubois L, Dubois C. Inhibition of platelet activation prevents the P-selectin and integrindependent accumulation of cancer cell microparticles and reduces tumor growth and metastasis in vivo. Int J Cancer. 2015;136:462-75.

90. Shirai Y, Shiba H, Sakamoto T, Horiuchi T, Haruki K, Fujiwara Y, Futagawa Y, Ohashi T, Yanaga K. Preoperative platelet to lymphocyte ratio predicts outcome of patients with pancreatic ductal adenocarcinoma after pancreatic resection. Surgery. 2015;158:360-5.

91. Chadha AS, Kocak-Uzel E, Das P, Minsky BD, Delclos ME, Mahmood U, Guha S, Ahmad M, Varadhachary GR, Javle M, et al. Paraneoplastic thrombocytosis independently predicts poor prognosis in patients with locally advanced pancreatic cancer. Act Oncol. 2015:54:971-8.

92. Thomas GM, Panicot-Dubois L, Lacroix R, Dignat-George F, Lombardo D, Dubois C. Cancer cell-derived microparticles bearing P-selectin glycoprotein ligand 1 accelerate thrombus formation in vivo. J Exp Med. 2009;206:1913-27.

93. Wang JG, Geddings JE, Aleman MM, Cardenas JC, Chantrathammachart P, Williams JC, Kirchhofer D, Bogdanov VY, Bach RR, Rak J, et al. Tumorderived tissue factor activates coagulation and enhances thrombosis in a mouse xenograft model of human pancreatic cancer. Blood. 2012;119: 5543-52.

94. Thaler J, Koder S, Kornek G, Pabinger I, Ay C. Microparticle-associated tissue factor activity in patients with metastatic pancreatic cancer and its effect on fibrin clot formation. Transl Res. 2014;163:145-50.

95. Woei-A-Jin FJSH, Tesselaar MET, Garcia Rodriguez P, Romijn FPHTM, Bertina RM, Osanto S. Tissue factor-bearing microparticles and CA19.9: two players in pancreatic cancer-associated thrombosis? Brit J Cancer. 2016;115:332-8.

96. Geddings JE, Hisada Y, Boulaftali Y, Getz TM, Whelihan M, Fuentes R, Dee R, Cooley BC, Key NS, Wolberg AS, et al. Tissue factor-positive tumor microvesicles activate platelets and enhance thrombosis in mice. J Thromb Haemost. 2016;4:153-66.

97. Dahlbäck B. Blood coagulation. Lancet. 2000;355:1627-32.

98. Gil-Bernabé AM, Ferjančič S, Tlalka M, Zhao L, Allen PD, Im JH, Watson K, Hill SA, Amirkhosravi A, Francis JL, et al. Recruitment of monocytes/ macrophages by tissue factor-mediated coagulation is essential for metastatic cell survival and premetastatic niche establishment in mice. Blood. 2012;119:3164-75.

99. Labelle M, Begum S, Hynes RO. Platelets quide the formation of early metastatic niches. P Natl Acad Sci USA. 2014;111:E3053-61.
100. Che SPY, Park JY, Stokol T. Tissue factor-expressing tumor-derived extracellular vesicles activate quiescent endothelial cells via proteaseactivated receptor-1. Front Oncol. 2017;7:261.

101. Schumacher D, Strilic B, Sivaraj KK, Wettschureck N, Offermanns S. Plateletderived nucleotides promote tumor-cell transendothelial migration and metastasis via P2Y, receptor. Cancer Cell. 2013;24:130-7.

102. Nieswandt B, Hafner M, Echtenacher B, Männel DN. Lysis of tumor cells by natural killer cells in mice is impeded by platelets. Cancer Res. 1999;59: 1295-300.

103. Palumbo JS, Talmage KE, Massari JV, La Jeunesse CM, Flick MJ, Kombrinck KW, Jirousková M, Degen JL. Platelets and fibrin(ogen) increase metastatic potential by impeding natural killer cell-mediated elimination of tumor cells. Blood. 2005;105:178-85.

104. Palumbo JS, Talmage KE, Massari JV, La Jeunesse CM, Flick MJ, Kombrinck KW, Hu Z, Barney KA, Degen JL. Tumor cell-associated tissue factor and circulating hemostatic factors cooperate to increase metastatic potential through natural killer cell-dependent and-independent mechanisms. Blood. 2007;110:133-41.

105. Martin MD, Matrisian LM. The other side of MMPs: protective roles in tumor progression. Cancer Metastas Rev. 2007;26:717-24.

106. Kopitz C, Gerg M, Bandapalli OR, Ister D, Pennington CJ, Hauser S, Flechsig C, Krell HW, Antolovic D, Brew K, et al. Tissue inhibitors of metalloproteinases-1 promotes liver metastasis by induction of hepatocyte growth factor signaling. Cancer Res. 2007;67:8615-23.

107. Schelter F, Grandl M, Seubert B, Schaten S, Hauser S, Gerg M, Boccaccio C, Comoglio P, Krüger A. Tumor cell-derived Timp-1 is necessary for maintaining metastasis-promoting met-signaling via inhibition of Adam-10. Clin Exp Metastas. 2011;28:793-802.

108. Gress TM, Müller-Pillasch F, Lerch MM, Friess H, Büchler M, Adler G. Expression and in-situ localization of genes coding for extracellular matrix proteins and extracellular matrix degrading proteases in pancreatic cancer. Int J Cancer. 1995;62:407-13.

109. Bramhall SR, Stamp GWH, Dunn J, Lemoine NR, Neoptolemos JP. Expression of collagenase (MMP2), stromelysin (MMP3) and tissue inhibitor of the metalloproteinases (TIMP1) in pancreatic and ampullary disease. Brit J Cancer. 1996;73:972-8.

110. Bramhall SR, Neoptolemos JP, Stamp GWH, Lemoine NR. Imbalance of expression of matrix metalloproteinases (MMPs) and tissue inhibitors of the matrix metalloproteinases (TIMPS) in human pancreatic carcinoma. J Pathol. 1997;182:347-55.

111. Crnogorac-Jurcevic T, Efthimiou E, Capelli P, Blaveri E, Baron A, Terris B, Jones M, Tyson K, Bassi C, Scarpa A, et al. Gene expression profiles of pancreatic cancer and stromal desmoplasia. Oncogene. 2001;20:7437-46.

112. Crnogorac-Jurcevic T, Efthimiou E, Nielsen T, Loader J, Terris B, Stamp G, Baron A, Scarpa A, Lemoine NR. Expression profiling of microdissected pancreatic adenocarcinomas. Oncogene. 2002;21:4587-94.

113. Schrötzlmair F, Kopitz C, Halbgewachs B, Lu F, Algül H, Brünner N, Gänsbacher B, Krüger A. Tissue inhibitor of metalloproteinases-1-induced scattered liver metastasis is mediated by host-derived urokinase-type plasminogen activator. J Cell Mol Med. 2010;14:2760-70.

114. Grünwald B, Harant V, Schaten S, Frühschütz M, Spallek R, Höchst B, Stutzer K, Berchtold S, Erkan M, Prokopchuk O, et al. Pancreatic premalignant lesions secrete tissue inhibitor of metalloproteinases-1, which activates hepatic stellate cells via CD63 signaling to create a premetastatic niche in the liver. Gastroenterology. 2016;151:1011-1024.e7.

115. Kobuch J, Cui H, Grünwald B, Saftig P, Knolle PA, Krüger A. TIMP-1 signaling via CD63 triggers granulopoiesis and neutrophilia in mice. Haematologica. 2015;100:1005-13.

116. Matsusue R, Kubo H, Hisamori S, Okoshi K, Takagi H, Hida K, Nakano K, Itami A, Kawada K, Nagayama S, et al. Hepatic stellate cells promote liver metastasis of colon cancer cells by the action of SDF-1/CXCR4 axis. Ann Surg Oncol. 2009;16:2645-53.

117. Saur D, Seidler B, Schneider G, Algül H, Beck R, Senekowitsch-Schmidtke R, Schwaiger M, Schmid RM. CXCR4 expression increases liver and lung metastasis in a mouse model of pancreatic cancer. Gastroenterology. 2005; 129:1237-50.

118. D'Costa Z, Jones K, Azad A, Van Stiphout R, Lim SY, Gomes AL, Kinchesh P, Smart SC, Gillies McKenna W, Buffa FM, et al. Gemcitabineinduced TIMP1 attenuates therapy response and promotes tumor growth and liver metastasis in pancreatic cancer. Cancer Res. 2017;77: 5952-62. 
119. Poruk KE, Firpo MA, Scaife CL, Adler DG, Emerson LL, Boucher KM, Mulvihill SJ. Serum osteopontin and TIMP-1 as diagnostic and prognostic biomarkers for pancreatic adenocarcinoma. Pancreas. 2013;42:193-7.

120. Malka D, Hammel P, Maire F, Rufat P, Madeira I, Pessione F, Lévy P, Ruszniewski P. Risk of pancreatic adenocarcinoma in chronic pancreatitis. Gut. 2002:51:849-52.

121. Costa-Silva B, Aiello NM, Ocean AJ, Singh S, Zhang H, Thakur BK, Becker A, Hoshino A, Mark MT, Molina $\mathrm{H}$, et al. Pancreatic cancer exosomes initiate pre-metastatic niche formation in the liver. Nat Cell Biol. 2015;17:816-26.

122. Robinson SM, Fan L, White SA, Charnley RM, Mann J. The role of exosomes in the pathogenesis of pancreatic ductal adenocarcinoma. International J Biochem Cell B. 2016;7:131-9.

123. Hoshino A, Costa-Silva B, Shen T, Rodrigues G, Hashimoto A. Tumor exosome integrins determine organotropic metastasis. Nature. 2016;27:329-35.

124. Sceneay J, Smyth MJ, Möller A. The pre-metastatic niche: finding common ground. Cancer Metastasis Rev. 2013;32(3-4):449-64.

125. Funamizu N, Hu C, Lacy C, Schetter A, Zhang G, He P, Gaedcke J, Ghadimi BM, Ried T, Yfantis HG, et al. Macrophage migration inhibitory factor induces epithelial to mesenchymal transition, enhances tumor aggressiveness and predicts clinical outcome in resected pancreatic ductal adenocarcinoma. Carcinogenesis. 2012;132:785-94.

126. Datta J, Vollmer CM Jr. Investigational biomarkers for pancreatic adenocarcinoma: where do we stand? South Med J. 2014;107:256-63.

127. Pavai S, Yap SF. The clinical significance of elevated levels of serum CA 19-9. Med J Malaysia. 2003:58:667-72.

128. Goonetilleke KS, Siriwardena AK. Systematic review of carbohydrate antigen (CA 19-9) as a biochemical marker in the diagnosis of pancreatic cancer. Eur J Surg Oncol. 2007;33:266-70

129. Duffy MJ, Sturgeon C, Lamerz R, Haglund C, Holubec VL, Klapdor R, Nicolini A Topolcan O, Heinemann V. Tumor markers in pancreatic cancer: a European group on tumor markers (EGTM) status report. Ann Oncol. 2010;21:441-7.

130. Melo SA, Luecke LB, Kahlert C, Fernandez AF, Gammon ST, Kaye J, LeBleu VS, Mittendorf EA, Weitz J, Rahbari N, et al. Glypican-1 identifies cancer exosomes and detects early pancreatic cancer. Nature. 2015;523:177-82.

131. Qian B, Pollard JW. Macrophage diversity enhances tumor progression and metastasis. Cell. 2010;141:39-51.

132. Mielgo A, Schmid MC. Impact of tumour associated macrophages in pancreatic cancer. BMB Rep. 2013;46:131-8.

133. Nielsen SR, Quaranta V, Linford A, Emeagi P, Rainer C, Santos A, Santos A, Ireland L, Sakai T, Sakai K, Kim YS, et al. Macrophage-secreted granulin supports pancreatic cancer metastasis by inducing liver fibrosis. Nat Cell Biol. 2016;18:549-60.

134. Sanford DE, Belt BA, Panni RZ, Mayer A, Deshpande AD, Carpenter D, Mitchem JB, Plambeck-Suess SM, Worley LA, Goetz BD, et al. Inflammatory monocyte mobilization decreases patient survival in pancreatic cancer: a role for targeting the CCL2/CCR2 axis. Clin Cancer Res. 2013;19:3404-15.

135. Schmid MC, Avraamides CJ, Foubert P, Shaked Y, Kang SW, Kerbel RS, Varner JA. Combined blockade of integrin-a4 $\beta 1$ plus cytokines SDF-1a or IL-1 $\beta$ potently inhibits tumor inflammation and growth. Cancer Res. 2011;71:6965-75.

136. Quaranta V, Rainer C, Nielsen SR, Raymant M, Ahmed MS, Engle D, Taylor A, Murray T, Campbell F, Palmer D, et al. Macrophage-derived granulin drives resistance to immune checkpoint inhibition in metastatic pancreatic cancer. BioRxiv. 2017; https://doi.org/10.1101/234906.

137. He Z, Ong CH, Halper J, Bateman A. Progranulin is a mediator of the wound response. Nat Med. 2003;9:225-9.

138. Elkabets M, Gifford AM, Scheel C, Nilsson B, Reinhardt F, Bray MA, Carpenter $A E$, Jirström K, Magnusson K, Ebert BL, et al. Human tumors instigate granulin-expressing hematopoietic cells that promote malignancy by activating stromal fibroblasts in mice. J Clin Invest. 2011;121:784-99.

139. Bao S, Ouyang G, Bai X, Huang Z, Ma C, Liu M, Shao R, Anderson RM, Rich $\mathrm{JN}$, Wang XF. Periostin potently promotes metastastic growth of colon cancer by augmenting cell survival via the Akt/PKB pathway. Cancer Cell. 2004:5:329-39.

140. Malanchi I, Santamaria-Martínez A, Susanto E, Peng H, Lehr HA, Delaloye JF, Huelsken J. Interactions between cancer stem cells and their niche governs metastatic colonization. Nature. 2011;481:85-9

141. Erez N. Fibroblasts form a hospitable metastatic niche in the liver. Nat Cell Biol. 2016;18:465-6.

142. Goedegebuure P, Mitchem JB, Porembka MR, Tan MCB, Belt BA, WangGillam A, Gillanders WE, Hawkins WG, Linehan DC. Myeloid-derived suppressor cells: general characteristics and relevance to clinical management of pancreatic cancer. Curr Cancer Drug Tar. 2011;11:734-51.

143. Gabrilovich DI. Myeloid-derived suppressor cells. Cancer Immunol Res. 2017; $5: 3-8$

144. Almand B, Clark Jl, Nikitina E, Van Beynen J, English NR, Knight SC, Carbone DP, Gabrilovich DI. Increased production of immature myeloid cells in cancer patients: a mechanism of immunosuppression in cancer. J Immunol. 2001;166:678-89.

145. Diaz-Montero CM, Salem ML, Nishimura MI, Garrett-Mayer E, Cole DJ, Montero AJ. Increased circulating myeloid-derived suppressor cells correlate with clinical cancer stage, metastatic tumor burden, and doxorubicincyclophosphamide chemotherapy. Cancer Immunol. 2009;58:49-59.

146. Zhang B, Wang Z, Wu L, Zhang M, Li W, Ding J, Zhu J, Wei H, Zhao K. Circulating and tumor-infiltrating myeloid-derived suppressor cells in patients with colorectal carcinoma. PLoS One. 2013:8:e57114.

147. OuYang L, Wu X, Ye S, Zhang R, Li Z, Liao W, Pan ZZ, Zheng LM, Zhang XS, Wang $Z$, et al. Tumor-induced myeloid-derived suppressor cells promote tumor progression through oxidative metabolism in human colorectal cancer. J Transl Med. 2015:13:47.

148. Zea AH, Rodriguez PC, Atkins MB, Hernandez C, Signoretti S, Zabaleta J, McDermott D, Quiceno D, Youmans A, O'Neill A, et al. Arginase-producing myeloid suppressor cells in renal cell carcinoma patients: a mechanism of tumor evasion. Cancer Res. 2005;65:3044-8.

149. Porembka MR, Mitchem JB, Belt BA, Hsieh C, Lee H, Herndon J, Gillanders WE, Linehan DC, Goedegebuure P. Pancreatic adenocarcinoma induces bone marrow mobilization of myeloid-derived suppressor cells which promote primary tumor growth. Cancer Immunol. 2012;61:1373-85.

150. Xu X, Hu J, Wang M, Peng F, Tian R, Guo XJ, Xie Y, Qin RY. Circulating myeloid-derived suppressor cells in patients with pancreatic cancer. Hepatob Pancreat Dis. 2016:15:99-105.

151. Khaled YS, Ammori BJ, Elkord E. Increased levels of granulocytic myeloidderived suppressor cells in peripheral blood and tumor tissue of pancreatic cancer patients. J Immunol Res. 2014;2014:879897.

152. Panni RZ, Sanford DE, Belt BA, Mitchem JB, Worley LA, Goetz BD, Mukherjee P, Wang-Gillam A, Link DC, Denardo DG, et al. Tumor-induced STAT3 activation in monocytic myeloid-derived suppressor cells enhances stemness and mesenchymal properties in human pancreatic cancer. Cancer Immunol. 2014;63:513-28.

153. Javeed N, Gustafson MP, Dutta SK, Lin Y, Bamlet WR, et al. Immunosuppressive CD14+HLA-DRlo/neg monocytes are elevated in pancreatic cancer and "primed" by tumor-derived exosomes. Oncoimmunology. 2017;6:e1252013.

154. Rodriguez PC, Ernstoff MS, Hernandez C, Atkins M, Zabaleta J, Sierra R, Ochoa AC. Arginase I-producing myeloid-derived suppressor cells in renal cell carcinoma are a subpopulation of activated granulocytes. Cancer Res. 2009;69:1553-60.

155. Serafini P, Borrello I, Bronte V. Myeloid suppressor cells in cancer: recruitment, phenotype, properties, and mechanisms of immune suppression. Semin Cancer Biol. 2006;16:53-65.

156. Gerner EW, Meyskens FL Jr. Polyamines and cancer: old molecules, new understanding. Nat Rev Cancer. 2004:4:781-92.

157. Schmielau J, Finn OJ. Activated granulocytes and granulocyte-derived hydrogen peroxide are the underlying mechanism of suppression of T-cell function in advanced cancer patients. Cancer Res. 2001;61:4756-60.

158. Nagaraj S, Gupta K, Pisarev V, Kinarsky L, Sherman S, Kang L, Herber D, Schneck J, Gabrilovich ID. Altered recognition of antigen is a novel mechanism of CD8+ T cell tolerance in cancer. Nat Med. 2007; 13:828-35

159. Nagaraj S, Schrum AG, Cho H, Celis E, Gabrilovich DI. Mechanism of T-cell tolerance induced by myeloid-derived suppressor cells. J Immunol. 2010; 184:3106-16.

160. Clark CE, Hingorani SR, Mick R, Combs C, Tuveson DA, Vonderheide RH. Dynamics of the immune reaction to pancreatic cancer from inception to invasion. Cancer Res. 2007:67:9518-27.

161. Stromnes IM, Brockenbrough S, Izeradjene K, Carlson MA, Cuevas C, Simmons RM, Greenberg PD, Hingorani SR. Targeted depletion of a MDSC subset unmasks pancreatic ductal adenocarcinoma to adaptive immunity. Gut. 2014:63:1769-81.

162. Liu C, Yu S, Kappes J, Wang J, Grizzle WE, Zinn KR, Zhang HG. Expansion of spleen myeloid suppressor cells represses NK cell cytotoxicity in tumorbearing host. Blood. 2007;109:4336-42. 
163. Li H, Han Y, Guo Q, Zhang M, Cao X. Cancer-expanded myeloid-derived suppressor cells induce anergy of NK cells through membrane-bound TGFB1. J Immunol. 2009;182:240-9.

164. Huang B, Pan PY, Li Q, Sato Al, Levy DE, Bromberg J, Divino CM, Chen SH. $\mathrm{Gr}-1+\mathrm{CD} 115+$ immature myeloid suppressor cells mediate the development of tumor-induced T regulatory cells and T-cell anergy in tumor-bearing host. Cancer Res. 2006;66:1123-31.

165. Liyanage UK, Moore TT, Joo HG, Tanaka Y, Herrmann V, Doherty G, Drebin JA, Strasberg SM, Eberlein TJ, Goedegebuure PS, et al. Prevalence of regulatory $T$ cells is increased in peripheral blood and tumor microenvironment of patients with pancreas or breast adenocarcinoma. J Immunol. 2002;169:2756-61.

166. Qu X, Zhuang G, Yu L, Meng G, Ferrara N. Induction of Bv8 expression by granulocyte colony-stimulating factor in CD11b+Gr1+ cells: key role of Stat3 signaling. J Biol Chem. 2012;287:19574-84.

167. Kujawski M, Kortylewski M, Lee H, Herrmann A, Kay H, Yu H. Stat3 mediates myeloid cell-dependent tumor angiogenesis in mice. J Clin Invest. 2008;118: 3367-77.

168. Yang L, DeBusk LM, Fukuda K, Fingleton B, Green-Jarvis B, Shyr Y, Matrisian LM, Carbone DP, Lin PC. Expansion of myeloid immune suppressor gr +CD11b+ cells in tumor-bearing host directly promotes tumor angiogenesis. Cancer Cell. 2004;6:409-21.

169. Melani C, Sangaletti S, Barazzetta FM, Werb Z, Colombo MP. Aminobiphosphonate-mediated MMP-9 inhibition breaks the tumor-bone marrow axis responsible for myeloid-derived suppressor cell expansion and macrophage infiltration in tumor stroma. Cancer Res. 2007;67:11438-46.

170. Steele CW, Karim SA, Leach JDG, Bailey P, Upstill-Goddard R, Rishi L, Foth M, Bryson S, McDaid K, Wilson Z, et al. CXCR2 inhibition profoundly suppresses metastases and augments immunotherapy in pancreatic ductal adenocarcinoma. Cancer Cell. 2016;29:832-45.

171. Ilkovitch D, Lopez DM. The liver is a site for tumor-induced myeloid-derived suppressor cell accumulation and immunosuppression. Cancer Res. 2009;69: 5514-21.

172. Connolly MK, Mallen-St Clair J, Bedroian AS, Malhotra A, Vera V, Ibrahim J, Henning J, Pachter HL, Bar-Sagi D, Frey AB, et al. Distinct populations of metastases-enabling myeloid cells expand in the liver of mice harboring invasive and preinvasive intra-abdominal tumor. J Leukoc Biol. 2010;87:713-25.

173. Zhao F, Obermann S, Von Wasielewski R, Haile L, Manns MP, Korangy F, Greten TF. Increase in frequency of myeloid-derived suppressor cells in mice with spontaneous pancreatic carcinoma. Immunology. 2009;128:141-9.

174. Bayne LJ, Beatty GL, Jhala N, Clark CE, Rhim AD, Stanger BZ, Vonderheide $\mathrm{RH}$. Tumor-derived granulocyte-macrophage colony-stimulating factor regulates myeloid inflammation and $T$ cell immunity in pancreatic cancer. Cancer Cell. 2012;21:822-35.

175. Song J, Lee J, Kim J, Jo S, Kim YJ, Baek JE, Kwon ES, Lee KP, Yang S, Kwon $K S$, et al. Pancreatic adenocarcinoma up-regulated factor (PAUF) enhances the accumulation and functional activity of myeloid-derived suppressor cells (MDSCs) in pancreatic cancer. Oncotarget. 2016;7:51840-53.

176. Mace TA, Ameen Z, Collins A, Wojcik S, Mair M, Young GS, Fuchs JR, Eubank TD, Frankel WL, Bekaii-Saab T, et al. Pancreatic cancer-associated stellate cells promote differentiation of myeloid-derived suppressor cells in a STAT3dependent manner. Cancer Res. 2013;73:3007-18.

177. Basso D, Gnatta E, Padoan A, Fogar P, Furlanello S, Aita A, Bozzato D, Zambon F, Arrigoni G, Frasson C, et al. PDAC-derived exosomes enrich the microenvironment in MDSCs in a SMAD4-dependent manner through a new calcium related axis. Oncotarget. 2017;8:84928-44.

178. Yachida S, Jones S, Bozic I, Antal T, Leary R, Fu B, Kamiyama M, Hruban RH, Eshleman JR, Nowak MA, et al. Distant metastasis occurs late during the genetic evolution of pancreatic cancer. Nature. 2010;467:1114-7.

179. Valastyan S, Weinberg RA. Tumor metastasis: molecular insights and evolving paradigms. Cell. 2011;147:275-92.

180. Kakkar AK, Lemoine NR, Scully MF, Tebbutt S, Williamson RC. Tissue factor expression correlates with histological grade in human pancreatic cancer. Brit J Surg. 1995;82:1101-4

181. Nitori N, Ino Y, Nakanishi Y, Yamada T, Honda K, Yanagihara K, Kosuge T, Kanai $Y$, Kitajima M, Hirohashi S. Prognostic significance of tissue factor in pancreatic ductal adenocarcinoma. Clin Cancer Res. 2005;11:2531-9.

182. Saito Y, Hashimoto Y, Kuroda J, Yasunaga M, Koga Y, Takahashi A, Matsumura $Y$. The inhibition of pancreatic cancer invasion-metastasis cascade in both cellular signal and blood coagulation cascade of tissue factor by its neutralisation antibody. Eur J Cancer. 2011;47:2230-9.
183. Krüger A, Soeltl R, Sopov I, Kopitz C, Arlt M, Magdolen V, Harbeck N, Gänsbacher B, Schmitt M. Hydroxamate-type matrix metalloproteinase inhibitor batimastat promotes liver metastasis. Cancer Res. 2001;61:1272-5.

184. Tester AM, Waltham M, Oh SJ, Bae SN, Bills MM, Walker EC, Kern FG, StetlerStevenson WG, Lippman ME, Thompson EW. Pro-matrix metalloproteinase-2 transfection increases orthotopic primary growth and experimental metastasis of MDA-MB-231 human breast cancer cells in nude mice. Cancer Res. 2004;64:652-8.

185. Kopitz C, Anton M, Gansbacher B, Krüger A. Reduction of experimental human fibrosarcoma lung metastasis in mice by adenovirus-mediated cystatin C overexpression in the host. Cancer Res. 2005;65:8608-12.

186. Yu Z, Zhao S, Ren L, Wang L, Chen Z, Hoffman RM, Zhou J. Pancreatic cancer-derived exosomes promote tumor metastasis and liver premetastatic niche formation. Oncotarget. 2017;8:63461-83.

187. Nuzhat Z, Kinhal V, Sharma S, Rice GE, Joshi V, Salomon C. Tumour-derived exosomes as a signature of pancreatic cancer - liquid biopsies as indicators of tumour progression. Oncotarget. 2017;8:17279-91.

188. Babic A, Wolpin BM. Circulating exosomes in pancreatic cancer: will they succeed on the long, littered road to early detection marker? Clin Chem. 2016:62:307-9.

189. Psaila B, Lyden D. The metastatic niche: adapting the foreign soil. Nat Rev Cancer. 2009:9:285-93.

190. Krüger A. Premetastatic niche formation in the liver: emerging mechanisms and mouse models. J Mol Med. 2015;93:1193-201.

191. Lai X, Wang M, McElyea SD, Sherman S, House M, Korc MA. microRNA signature in circulating exosomes is superior to exosomal glypican-1 levels for diagnosing pancreatic cancer. Cancer Lett. 2017;393:86-93.

192. Madhavan B, Yue S, Galli U, Rana S, Gross W, Müller M, Giese NA, Kalthoff H, Becker T, Büchler MW, et al. Combined evaluation of a panel of protein and miRNA serum-exosome biomarkers for pancreatic cancer diagnosis increases sensitivity and specificity. Int J Cancer. 2015;136:2616-27.

193. Que R, Ding G, Chen J, Cao L. Analysis of serum exosomal microRNAs and clinicopathologic features of patients with pancreatic adenocarcinoma. World J Surg Oncol. 2013;11:219.

194. Kahlert C, Melo SA, Protopopov A, Tang J, Seth S, Koch M, Zhang J, Weitz J, Chin L, Futreal A, et al. Identification of double-stranded genomic DNA spanning all chromosomes with mutated KRAS and p53 DNA in the serum exosomes of patients with pancreatic cancer. J Biol Chem. 2014;289:3869-75.

\section{Ready to submit your research? Choose BMC and benefit from:}

- fast, convenient online submission

- thorough peer review by experienced researchers in your field

- rapid publication on acceptance

- support for research data, including large and complex data types

- gold Open Access which fosters wider collaboration and increased citations

- maximum visibility for your research: over $100 \mathrm{M}$ website views per year

At BMC, research is always in progress.

Learn more biomedcentral.com/submissions 